\title{
Descripción del último estado larvario y recopilación de registros de hospederos de siete especies de Tortrícidos de importancia económica en Chile (Lepidoptera: Tortricidae)
}

\section{Description of the last larval stage and a compilation of host records, of seven species of Tortricids of economic importance in Chile (Lepidoptera: Tortricidae)}

\author{
Danilo E. Ceppeda ${ }^{1} \&$ Guadalupe E. Cubillos ${ }^{2}$ \\ ${ }^{1}$ Museo Entomológico Luis Peña, Departamento de Sanidad Vegetal, Facultad de Ciencias Agronómicas, Universidad de \\ Chile.museoent@uchile.cl, casilla 20, Santiago, Chile. \\ 2 Fuenzalida Urrejola 923, La Cisterna, Santiago, Chile. \\ Email: lupcub@gmail.com.
}

\begin{abstract}
RESUMEN
Se entregan nuevos antecedentes para siete especies de Tortrícidos de importancia económica en Chile, de acuerdo al estudio de ejemplares criados en condiciones de laboratorio. Esto comprende, principalmente, una descripción del último estado larvario basada en la quetotaxia, una recopilación de registros de hospederos y nuevas citas.
\end{abstract}

Palabras clave: Cydia, Grapholita, Lobesia, Chileulia, Proeulia, quetotaxia.

\begin{abstract}
New records are presented for seven species of economically important Tortricids occurring in Chile. The study was mainly based on local material reared under laboratory conditions. This includes a description of the last larval stage based on chaetotaxy and a compilation of hosts records.
\end{abstract}

Keywords: Cydia, Grapholita, Lobesia, Chileulia, Proeulia, chaetotaxy.

\section{INTRODUCCIÓN}

Las observaciones biológicas en larvas de algunos Tortrícidos de Chile se ha asociado con especies que han provocado importantes pérdidas desde el punto de vista económico. No sólo como plagas con daños directos en la producción, sino también como agentes causales de rechazo por restricciones cuarentenarias. Estos aportes corresponden a descripciones y observaciones morfológicas, no fundamentadas en el estudio de quetotaxia. Como por ejemplo, Campos et. al. (1981) y Álvarez \& González (1982) para la especie Proeulia auraria (Clarke); González (1983) para Chileulia stalactitis (Meyrick). Con posterioridad, González (1989, 1990, 2003) aporta descripciones y figuras de larvas, de las especies plaga más importantes de la familia Tortricidae: Crocidosema aporema (Walsingham), Cydia pomonella (L), Grapholita molesta (Busck) y algunas especies del taxón Proeulia spp.
Recientemente,Vargas (2006, 2007a) entrega descripciones detalladas de la quetotaxia, del último estado larvario y pupa, para dos especies de Tortrícidos presentes en Chile. Estas corresponden a Cryptophlebia cortesi Clarke y Cydia largo Heppner, en base a material colectado y asociado a la Acacia macracantha Bonpl \& Humb ex Willd y a una especie de Prosopis.

Desde el punto de vista del alto grado de polifagia del grupo, Brown \& Passoa (1998) entregan, para la tribu Euliini un listado con más de 36 familias vasculares de hospederos para 11 taxones previamente conocidos.

Cabe destacar que ante la identificación en Chile, el 14 de abril del 2008, de poblaciones de la polilla del racimo Lobesia botrana (Denis \& Schiffermüller), se declara su control oficial por parte de los órganos competentes (Diario 
Oficial 2008). En consecuencia, el estado actual de las especies plagas en nuestro país está conformado al menos de cuatro de primera importancia económica.

Los estudios morfológicos sistemáticos, que tiendan a una correcta identificación de insectos plagas, constituye el primer paso en promover decisiones de estudios o control. Por lo tanto nuestro trabajo tiene por objetivo la descripción del último estado larvario, de acuerdo al estudio de ejemplares criados en condiciones de laboratorio, basado en el estudio de quetotaxia, una recopilación con registros de hospederos y el aporte de nuevas citas.

\section{MATERIALES Y MÉTODOS}

Los estudios morfológicos se fundamentan en ejemplares criados en condiciones de laboratorio, obtenidos en colectas de terreno. Estas han sido realizadas desde el año 2002 y con posterioridad durante los años 2008 a 2010, desde principios de la temporada en primavera hasta fines del verano. Parte de las larvas colectadas fueron colocadas en contenedores de plástico con material vegetativo, del cual fue colectada, a temperatura ambiente. De los adultos obtenidos de las crianzas se realizaron observaciones de genitalia comparada, con la finalidad de identificar y confirmar a la especie en estudio, con tal propósito se utilizaron los siguientes trabajos taxonómicos, Obraztsov (1964) y Razowski $(1995,1999)$.

Para el estudio de la quetotaxia en las larvas se utilizó una variante de la metodología del trabajo de Vargas (2006), esto comprendió 81 preparaciones permanentes en bálsamo de Canadá del tegumento, previamente teñidas con fucsina ácida. Este material biológico está depositado en la colección del Museo Entomológico Luis Peña del Departamento de Sanidad Vegetal, Facultad de Ciencias Agronómicas, de la Universidad de Chile (MEUC). La nomenclatura utilizada en la descripción de la quetotaxia de las larvas y otros detalles morfológicos están basados en los aportes de Hinton (1946), MacKay (1959,1962), Hetz \& Werner (1980), Stehr (1987), Vargas (2006) y Passoa (2008). Respecto a la terminología utilizada en la descripción de antenas, está basado en el trabajo de Vargas (2007b). Las observaciones de las preparaciones microscópicas se realizaron con microscopio Leitz de $12 \mathrm{X}$; en cambio para larvas no preparadas y adultos se utilizó lupa estereoscópica Leitz 12,5 X.

\section{RESULTADOS}

\section{Cydia pomonella (L)}

(Figuras 1-8)

Diagnosis: Larva de color general del cuerpo blanco gris o rosado, longitud máxima de $21 \mathrm{~mm}$. Cabeza de color castaño, con pequeñas manchas dispersas de tonalidad más oscura; antenas de tonalidad castaño-clara. Labro de forma bilobulado, con 12 setas ubicadas sobre la superficie externa y 6 gruesas en la cara interna; espínulas de la epifaringe cortas, poco densas, ubicadas mayormente en la base del labro. Mandíbulas de tonalidad castaño-oscuras, fuertemente quitinizadas con 5 dientes, siendo los tres apicales más prominentes. Espinerete simple, alongado y de forma subcilíndrica; palpos labiales cilíndricos y menor a la mitad del largo respecto del espinerete. Protórax con placa torácica destacada, de color castaño claro, con pequeñas manchas dispersas, de tonalidad más oscuras, surco medio dorsal destacado; espiráculo de forma ovoidal. Patas bien quitinizadas, fémur, tibia y tarso de color castaño claro y con garra del tarso simple. Abdomen con espiráculos de forma ovoidal, siendo el de A8 de tamaño mayor en diámetro que los precedentes y separado cerca de la mitad de su diámetro del pináculo. Espuripedios con crochets dispuestos en bandas uniordinales. Placa anal bien destacada, de color similar a la placa protorácica; peine anal ausente. Tegumento del cuerpo recubierto de microprocesos de forma aguda.

Antena: Primer segmento anular y corto. Segundo segmento cilíndrico, alongado, presenta un sensilo campaniforme ubicado cerca de la base. Posee, además, cinco sensilos: dos tricodeos, siendo el más pequeño tres veces menor al largo del segmento, ubicado en el tercio superior y tres sensilos basicónicos. Tercer segmento cilíndrico y corto, cerca de cuatro veces menor respecto del largo del segundo, posee además tres sensilos, uno estilocónico y dos basicónicos.

\section{Quetotaxia del último estado:}

Cabeza: 6 estemas de forma semicircular. Estema 5 desplazado levemente hacia la zona anterior, en comparación a los demás que forman un semicírculo; seta $\mathrm{S} 1$ postero a estema 3; S2 postero ventral a estema 1; S3 postero ventral a S2; seta SS2 antero ventral a estema 6; seta SS3 postero ventral a SS2; SS1 antero ventral a SS3; A1, A2, A3 y L1 no alineadas de forma recta; $\mathrm{AF} 1, \mathrm{AFa}$ y $\mathrm{AF} 2$ presentes; $\mathrm{V} 1$, V2, Va y V3 presentes.

Tórax: Protórax con placa torácica bien destacada, surco medio dorsal presente. Seta SD1 usualmente más cerca a SD2 que a XD2. Seta MXD1 equidistante a D1 y D2, ubicada dentro de la placa. Grupo de setas L inserto en pináculo de forma elíptica, ubicado de forma anteroventral al espiráculo, L1 por lo general no alineada con respecto a L2 y L3. Grupo de setas SV bisetosos, ubicado sobre pináculo ventral al del grupo L. V1 presente sobre pináculo de forma circular. Mesotórax y metatórax con grupo de setas D bisetosos, con ambas setas ubicadas sobre un mismo pináculo, D1 
en posición dorsal a D2. Grupo SD bisetosos, ambas setas ubicadas sobre el mismo pináculo. MSD1 y MSD2 en un mismo pináculo. L2 y L1 ubicadas sobre pináculo de forma elíptica, en posición anteroventral al pináculo que contiene a L3. Grupo SV unisetoso sobre pináculo de forma circular, ubicado posteroventral al pináculo de L3. Pináculo de V1 ubicado muy cerca de la base de la coxa.

Abdomen: A1, A2 y A7 con grupo D bisetoso, con ambas setas ubicadas sobre pináculos separados, D1 anterodorsal a D2. Grupo SD bisetoso, con SD2 notablemente reducida, ubicadas en un mismo pináculo. Setas L1 y L2 sobre un mismo pináculo y ubicadas ventral al espiráculo, en relación a L3 ubicada anterodorsal. V1 sobre pináculo de forma circular y ubicada en forma central del segmento. A3-A6 con grupo D bisetoso, ubicados sobre pináculos separados, D1 anterodorsal a D2. Grupo SD bisetoso con SD2 notablemente reducida, ubicadas en un mismo pináculo. Setas L1 y L2 sobre un mismo pináculo y ubicadas ventral al espiráculo, en relación a L3, ubicada anterodorsal. Grupo SV trisetoso ubicadas sobre un mismo pináculo. V1 ubicada en la base del espuripedio. A8 similar a A1 y A2, pero con grupo SD ubicado de forma anterior al espiráculo, siendo su diámetro menor a la mitad del diámetro del pináculo. SV bisetoso ubicado sobre un mismo pináculo. V1 ubicada de forma posterior al centro del segmento. En A9 seta D1 sobre un mismo pináculo que SD1; D2 sobre un gran pináculo ensanchado y ubicado en posición dorsal. Grupo L trisetoso, dispuesto o no sobre un mismo pináculo; grupo SV unisetoso. V1 ubicada de forma posterior al centro del segmento. A10 con placa anal bien diferenciada, con 4 pares de setas, D1 antero ventral a D2, SD1 posterodorsal a SD2 y posteroventral a D1; grupo L trisetoso y ubicado en pináculo de forma oblonga.

Variaciones intraespecíficas: En segmentos A1, A2, el grupo SV, se encontró setas uni, bi y trisetoso, sobre un mismo pináculo. En segmento A7, el grupo SV puede ser uni, bi o trisetoso. En segmento A8, grupo SV puede ser uni o bisetoso. En segmento A9, el grupo L trisetoso puede estar en un mismo pináculo o L1 y L2 separados de L3, caracteres ya observados por MacKay (1959).

Hospederos: Esencialmente pomáceas y carozos (González 2003).

Material examinado: 10 preparaciones microscópicas, La Pintana, provincia de Santiago, Región Metropolitana, marzo, 1999, Coll. D.E. Cepeda, crianza de laboratorio, en Juglans regia (4 ejemplares de $5^{\circ}$ estado); El Olivar, provincia de Cachapoal, Región del Libertador General Bernardo O’Higgins, 14 diciembre, 2006, Coll. D.E. Cepeda, crianza de laboratorio, en Malus domestica (3 ejemplares de $5^{\circ}$ estado); Los Niches, provincia de Curicó, Región del Maule, 28 de noviembre 2008, Coll. G.E. Cubillos, crianza de laboratorio, en Malus domestica (3 ejemplares de $5^{\circ}$ estado).

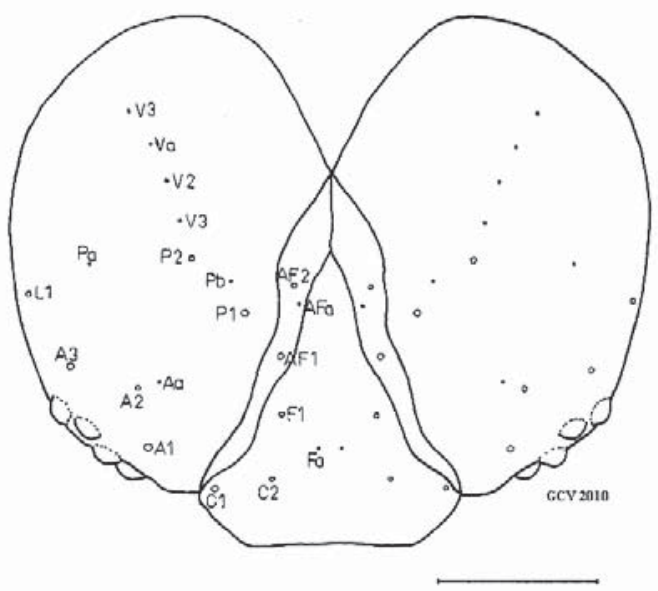

Figura 1. Larva de Cydia pomonella. Quetotaxia de cabeza en vista frontal. Escala: 0,5 mm.

Figure 1. Cydia pomonella larvae. Chaetotaxy of head in frontal view. Scale: $0.5 \mathrm{~mm}$. 


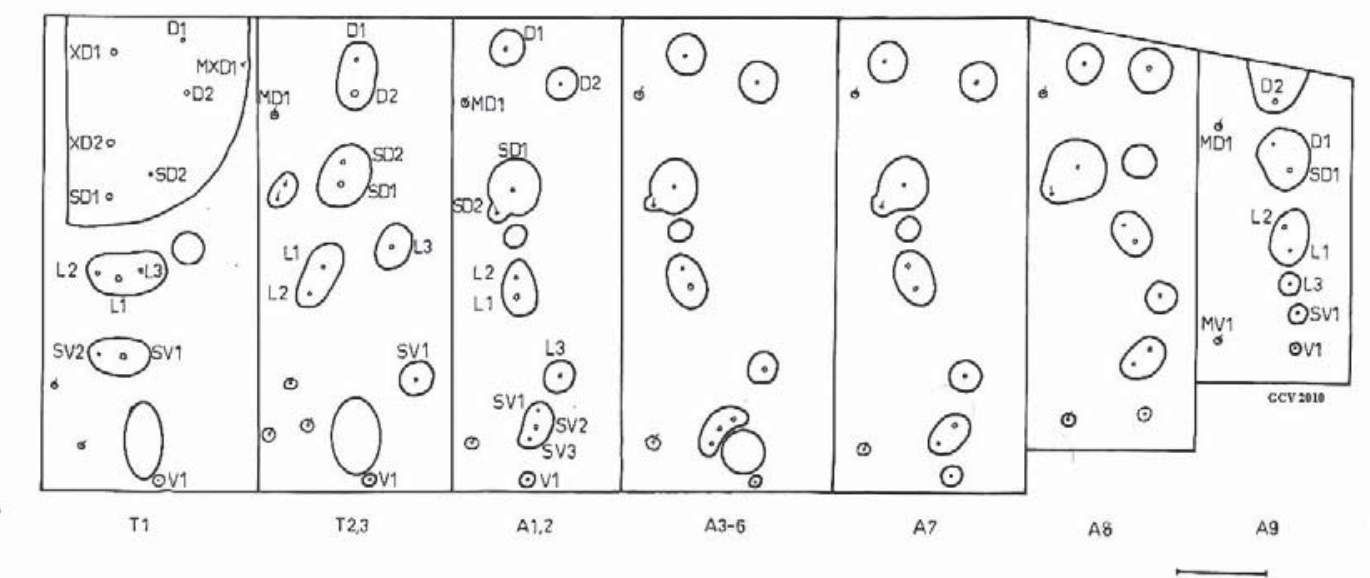

FIgURA 2. Larva de Cydia pomonella. Quetotaxia de tórax y abdomen en vista lateral. Escala: 0,5 mm.

Figure 2. Cydia pomonella larvae. Chaetotaxy of thorax and abdomen in lateral view. Scale: $0.5 \mathrm{~mm}$.

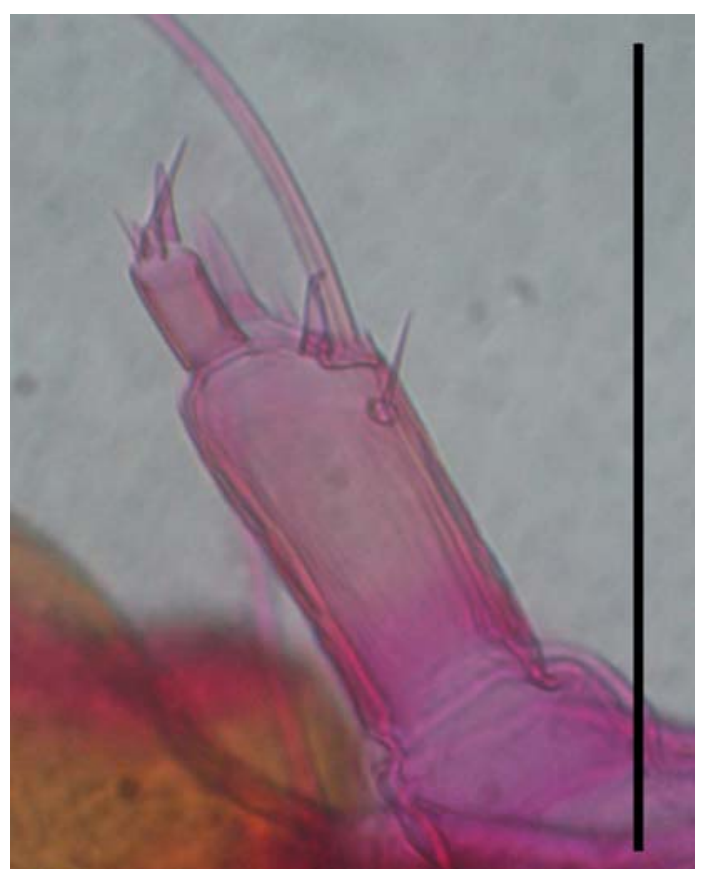

Figura 3. Larva de Cydia pomonella. Antena. Escala: 0,5 mm. Figure 3. Cydia pomonella larvae. Antennae. Scale $0.5 \mathrm{~mm}$.

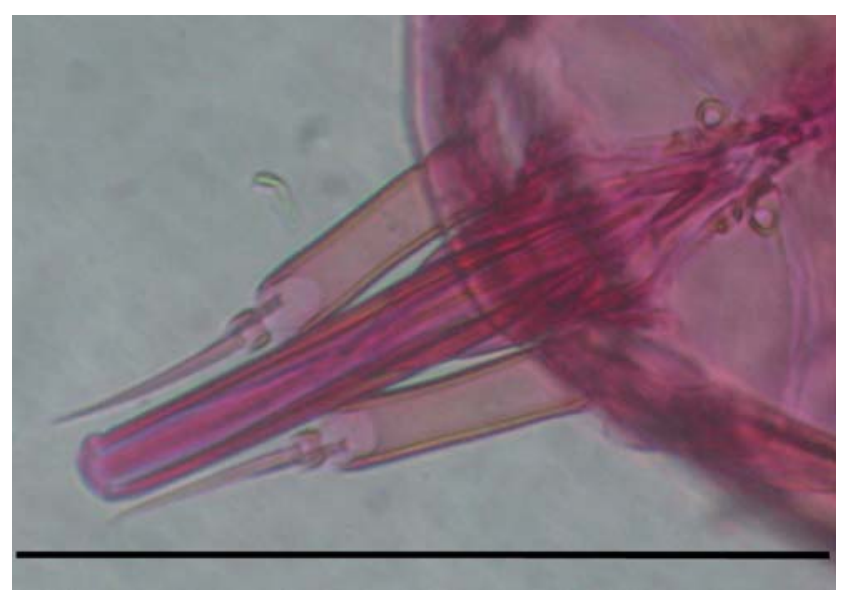

Figura 4. Larva de Cydia pomonella. Espinerete. Escala: 0,5 mm. Figure 4. Cydia pomonella larvae. Spinneret. Scale: $0.5 \mathrm{~mm}$. 


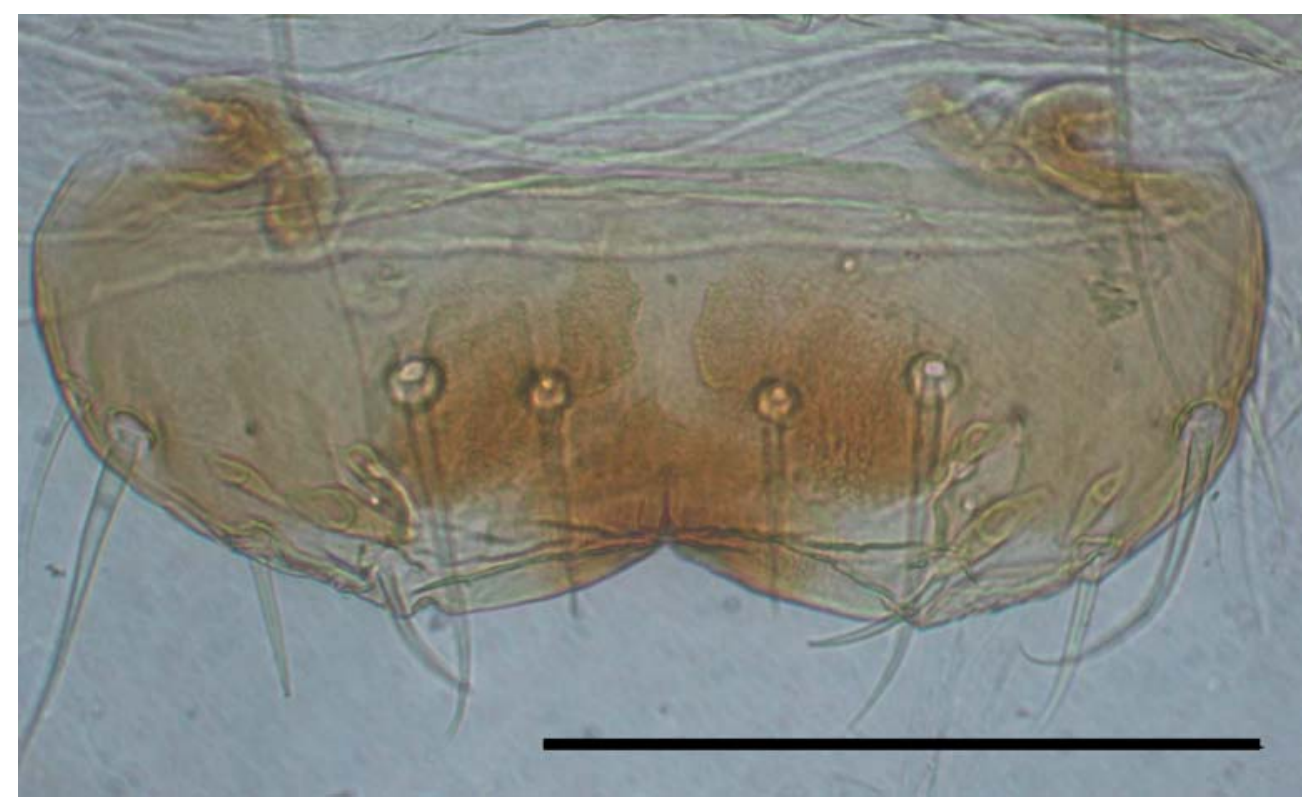

Figura 5. Larva de Cydia pomonella. Labro. Escala: 0,5 mm.

Figure 5. Cydia pomonella larvae. Labrum. Scale: $0.5 \mathrm{~mm}$.

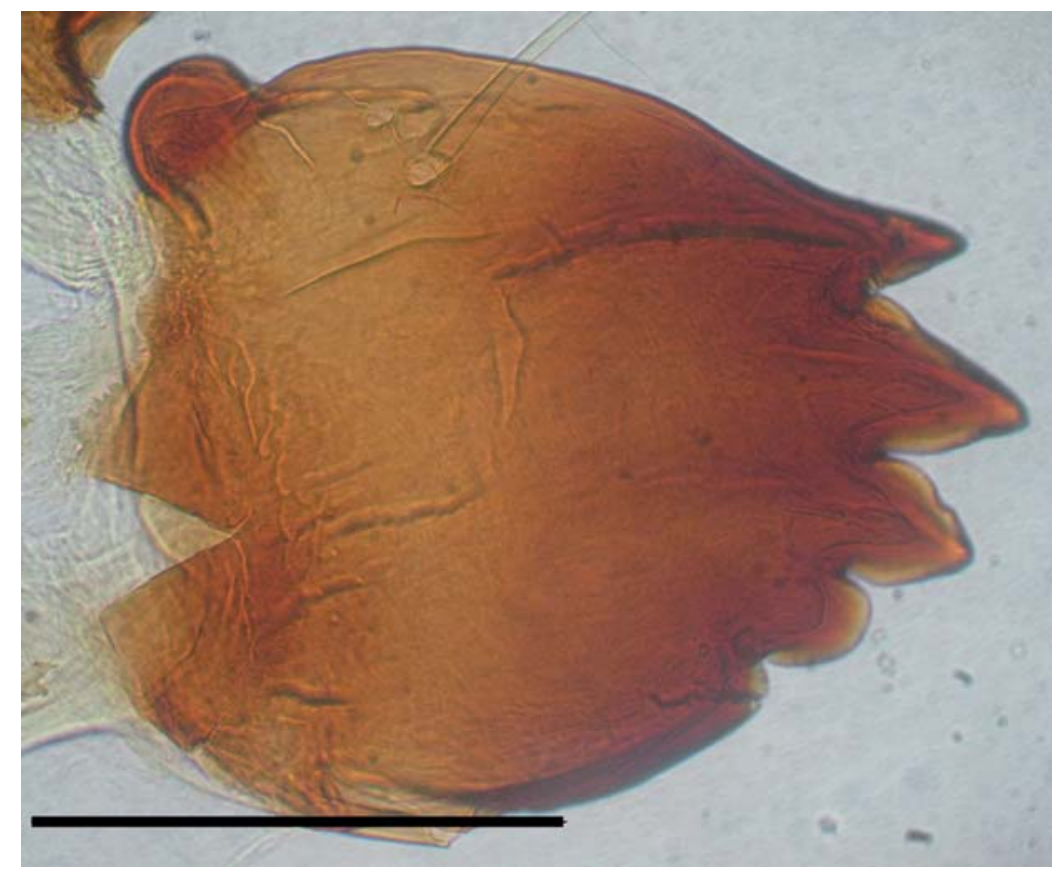

Figura 6. Larva de Cydia pomonella. Mandíbula. Escala: 0,5 mm.

Figure 6. Cydia pomonella larvae. Mandible. Scale: $0.5 \mathrm{~mm}$. 


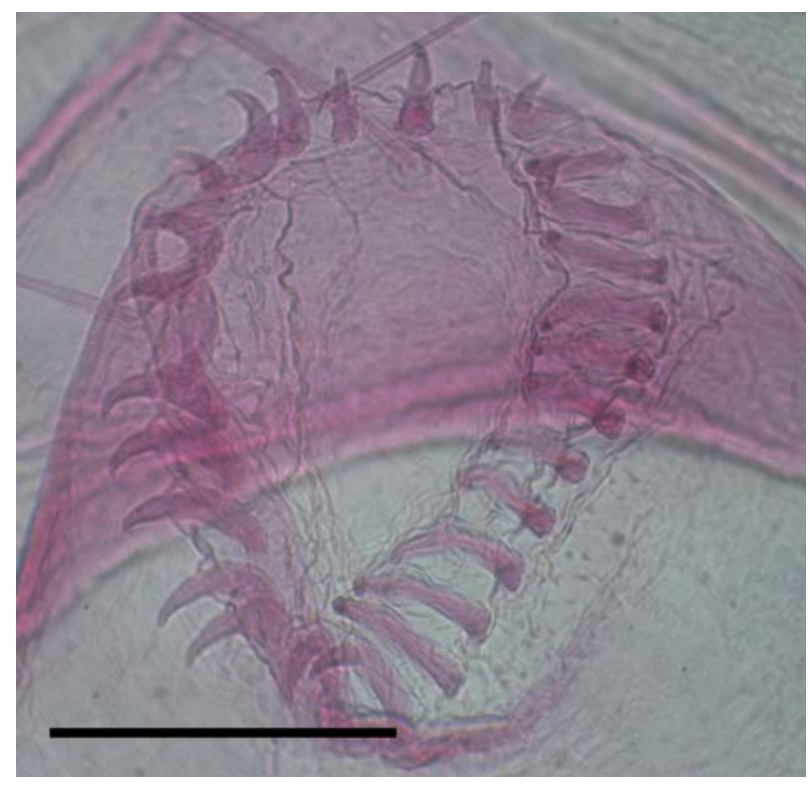

FIgURA 7. Larva de Cydia pomonella. Crochets. Escala: 0,5 mm.

Figure 7. Cydia pomonella larvae. Crochets. Scale: $0.5 \mathrm{~mm}$.

\section{Grapholita molesta (Busck)}

(Figuras 9 - 16)

Diagnosis: Larva de color general del cuerpo blanco a rosado pálido, longitud máxima de $15 \mathrm{~mm}$. Cabeza de color castaño, con pequeñas manchas dispersas de tonalidad más oscura, leve mancha castaña al inicio de la gena y en la zona interna del área estematal; antenas de tonalidad castaña clara. Labro de forma bilobulado, con 12 setas ubicadas sobre la superficie externa y 6 gruesas en la cara interna; espínulas de la epifaringe alargadas, poco densas, ubicadas mayormente en la base del labro. Mandíbulas de tonalidad castaña, fuertemente quitinizadas con 5 dientes, siendo los tres apicales prominentes y agudos. Espinerete simple, alargado y de terminación aguda, levemente curvado; palpos labiales cilíndricos y menor a la mitad del largo con respecto al espinerete. Protórax con placa torácica notoria, de tonalidad clara, surco medio dorsal destacado; espiráculo de forma ovoidal. Patas quitinizadas, fémur, tibia y tarso de color general del cuerpo y con garra del tarso simple. Abdomen con espiráculos de forma ovoidal, siendo el de A8 de tamaño mayor en diámetro que los precedentes y levemente separado del pináculo. Espuripedios con crochets dispuestos en bandas uniordinales. Placa anal bien destacada, de color similar a la placa protorácica; peine anal presente de 5 a 8 dientes. Tegumento del cuerpo recubierto de microprocesos de forma aguda.

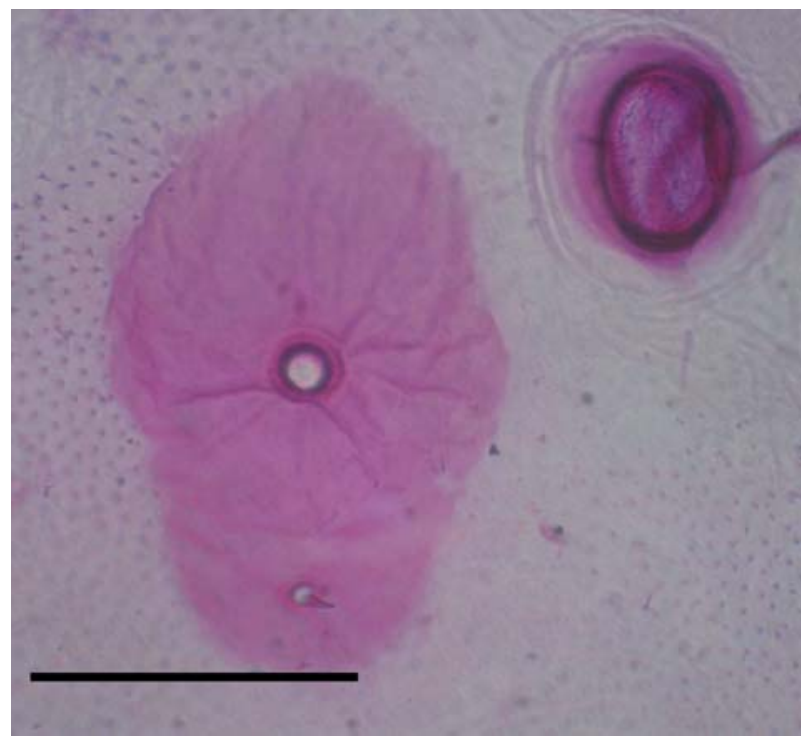

Figura 8. Larva de Cydia pomonella. Detalle de SD1, SD2 y espiráculo en A8. Escala: 0,5 mm.

FIGURE 8. Cydia pomonella larvae. Details SD1, SD2 and spiracle on A8. Scale: $0.5 \mathrm{~mm}$.

Antena: Primer segmento anular y corto. Segundo segmento cilíndrico, corto, presenta un sensilo campaniforme ubicado cerca de la base. Posee, además, cinco sensilos: dos tricodeos, siendo el más pequeño tres veces menor al largo del segmento, ubicado en el tercio superior y tres sensilos basicónicos. Tercer segmento cilíndrico y corto, cerca de tres y media veces menor respecto del largo del segundo, posee, además, tres sensilos, uno estilocónico y dos basicónicos.

\section{Quetotaxia del último estado:}

Cabeza: 6 estemas de forma semicircular. Estema 5 desplazado levemente hacia la zona anterior, en comparación a los demás que forman un área ocelar más angular que redondeada; seta $\mathrm{S} 1$ postero a estema 3; S2 posteroventral a estema 1; S3 posteroventral a S2; seta SS2 anteroventral a estema 6; seta SS3 posteroventral a SS2; SS1 anteroventral a SS3; A1, A2, A3 y L1 no alineadas de forma recta; AF1, AFa y AF2 presentes. V1, V2, Va y V3 presentes.

Tórax: Protórax con placa torácica bien destacada, surco medio dorsal presente. Seta SD1 notablemente cercana a SD2 que a XD2. Seta MXD1 más cerca de D1 que a D2. Grupo de setas L insertas en pináculo de forma reniforme u oblongo, ubicado anteroventral al espiráculo, seta L1 
no alineada con respecto a L2 y L3. Grupo de setas SV bisetosos, ubicado sobre pináculo ventral al del grupo L. V1 ubicado sobre pináculo de forma circular. Mesotórax y metatórax con grupo de setas D bisetosos, con ambas setas ubicadas sobre un mismo pináculo, D1 en posición dorsal a D2. Grupo SD bisetosos, con ambas setas sobre el mismo pináculo. MSD1 y MSD2 ubicadas sobre un mismo pináculo. L2 y L1 sobre pináculo de forma elíptica, ubicado en posición anteroventral al pináculo que contiene a L3. Grupo SV unisetoso, sobre pináculo de forma circular, ubicado posteroventral al pináculo de L3. V1 ubicado en la base de la coxa.

Abdomen: A1 y A2 con grupo D bisetoso con ambas setas ubicadas sobre pináculos separados, D1 anterodorsal a D2. Grupo SD bisetoso, con SD2 ubicada en un mismo pináculo o separado a SD1. Setas L1 y L2 sobre un mismo pináculo y ubicadas ventral al espiráculo, en relación a L3 ubicada anterodorsal. Grupo de SV pueden ser bi o trisetosos. V1 sobre pináculo de forma circular y ubicada en forma central del segmento. A3-A6 con grupo D bisetoso, ubicados sobre pináculos separados, D1 anterodorsal a D2. Grupo SD bisetoso con SD2 ubicadas en un mismo pináculo o separado a SD1. Setas L1 y L2 sobre un mismo pináculo y ubicadas ventral al espiráculo, en relación a L3 ubicada anterodorsal. Grupo SV por lo general trisetoso. V1 ubicadas en la base del espuripedio. A7 similar a A1 y A2 pero con grupo SV bisetoso. A8 similar a A1 y A2 pero con grupo SD ubicado de forma anterior al espiráculo, con SD2 ubicada en un mismo pináculo que SD1, el diámetro del espiráculo es menor a la mitad del diámetro del pináculo y grupo SV bisetoso, ubicado sobre un mismo pináculo. V1 ubicada de forma central del segmento. En A9 seta D1 sobre un mismo pináculo que SD1; D2 sobre un amplio pináculo de forma subrectangular. Grupo $\mathrm{L}$ trisetoso, dispuesto sobre un mismo pináculo; grupo SV puede ser uni o bisetoso. V1 ubicada de forma posterior al centro del segmento. A10 con placa anal bien diferenciada, con 4 pares de setas, D1 antero ventral a D2, SD1 posterodorsal a SD2 y posteroventral a $\mathrm{D} 1$; grupo $\mathrm{L}$ trisetoso y ubicado en pináculo de forma oblonga.

Variaciones intraespecíficas: El grupo SV en segmento A1 y A2 puede ser bi o trisetoso y en segmento A9 puede ser mono o bisetoso, caracteres ya mencionados por MacKay (1959). En nuestras observaciones desde segmentos A17, seta SD2 muestra una amplia variabilidad, al estar en un mismo pináculo o separado a SD1, incluso dentro del mismo segmento.

Hospederos: Esencialmente carozos y pomáceas (González 2003).

Material examinado: 10 preparaciones microscópicas, La Pintana, provincia de Santiago, Región Metropolitana, 28 de noviembre, 2002, Coll. D.E. Cepeda, crianza de laboratorio, en Prunus avium (4 ejemplares de $5^{\circ}$ estado); Padre Hurtado, provincia de Talagante, Región Metropolitana, 27 de febrero, 2000, Coll. D.E. Cepeda, crianza de laboratorio, en Prunus domestica (3 ejemplares de $5^{\circ}$ estado); Teno, provincia de Curicó, Región del Maule, 5 de enero, 1988, Coll. R.H. González, crianza de laboratorio, en Malus domestica (3 ejemplares de $5^{\circ}$ estado).

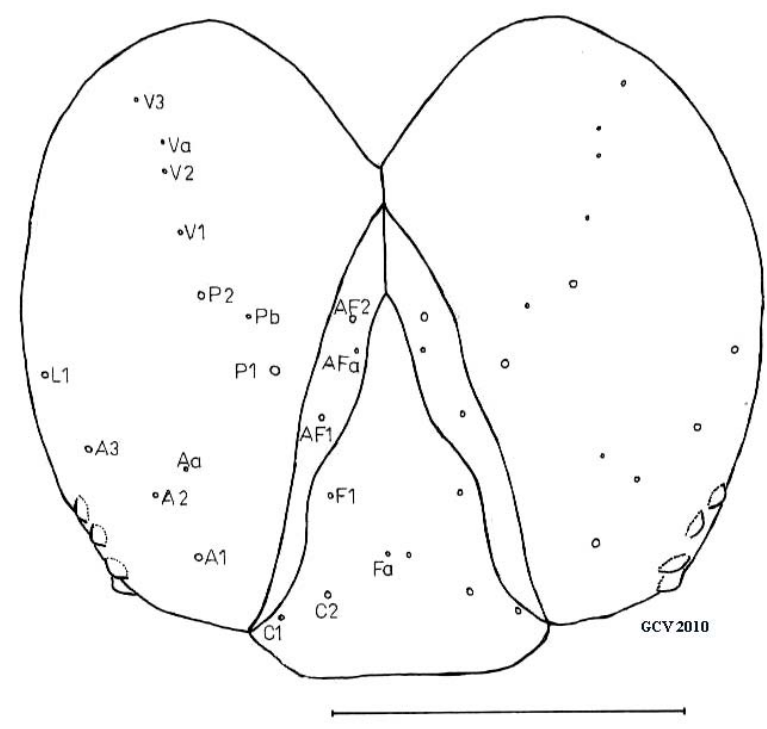

FIGURA 9. Larva de Grapholita molesta. Quetotaxia de cabeza en vista frontal. Escala: 0,5 mm.

Figure 9. Grapholita molesta larvae. Chaetotaxy of head in frontal view. Scale: $0.5 \mathrm{~mm}$. 


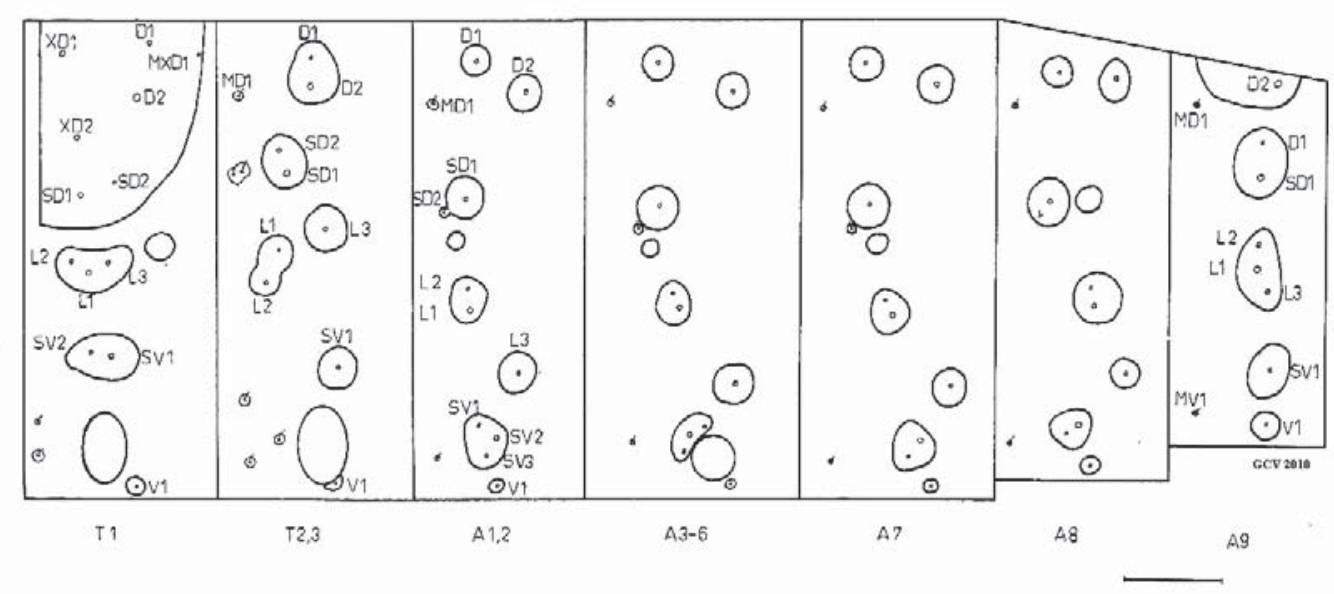

Figura 10. Larva de Grapholita molesta. Quetotaxia de tórax y abdomen en vista lateral. Escala: 0,5 mm. FIGURE 10. Grapholita molesta larvae. Chaetotaxy of thorax and abdomen in lateral view. Scale: $0.5 \mathrm{~mm}$.

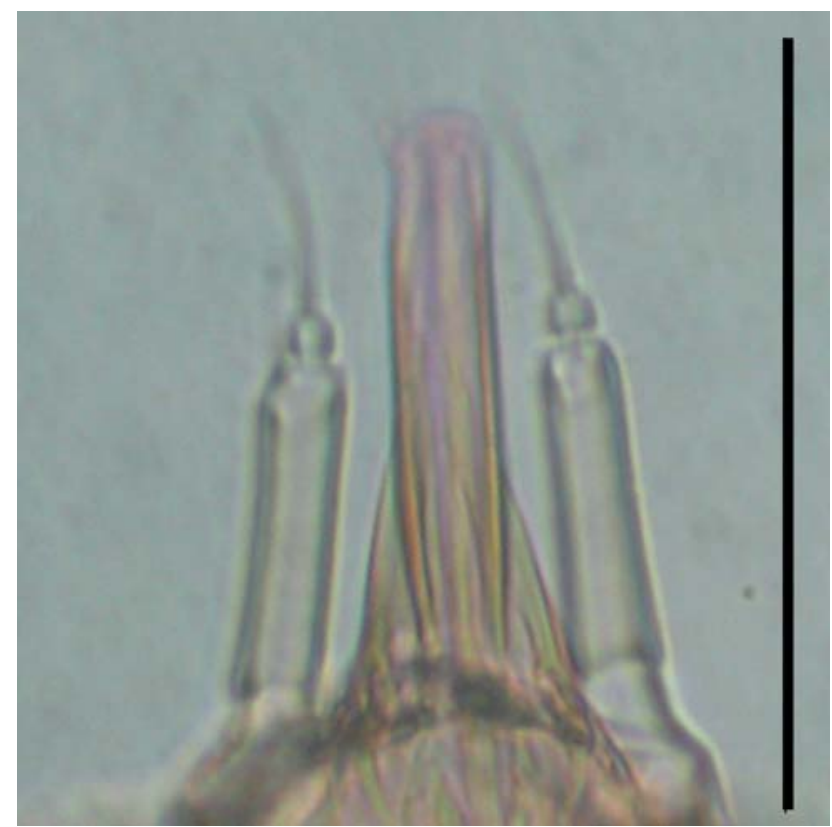

Figura 11. Larva de Grapholita molesta. Espinerete. Escala: 0,1 mm. Figura 12. Larva de Grapholita molesta. Labro. Escala: 0,1 mm. FIGURE 11. Grapholita molesta larvae. Spinneret. Scale: $0.1 \mathrm{~mm}$.

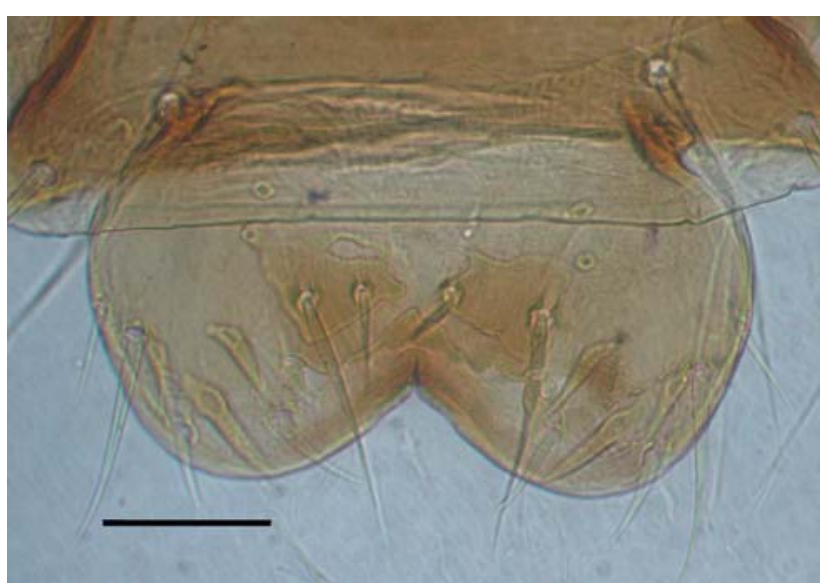

FIGURE 12. Grapholita molesta larvae. Labrum. Scale: $0.1 \mathrm{~mm}$. 


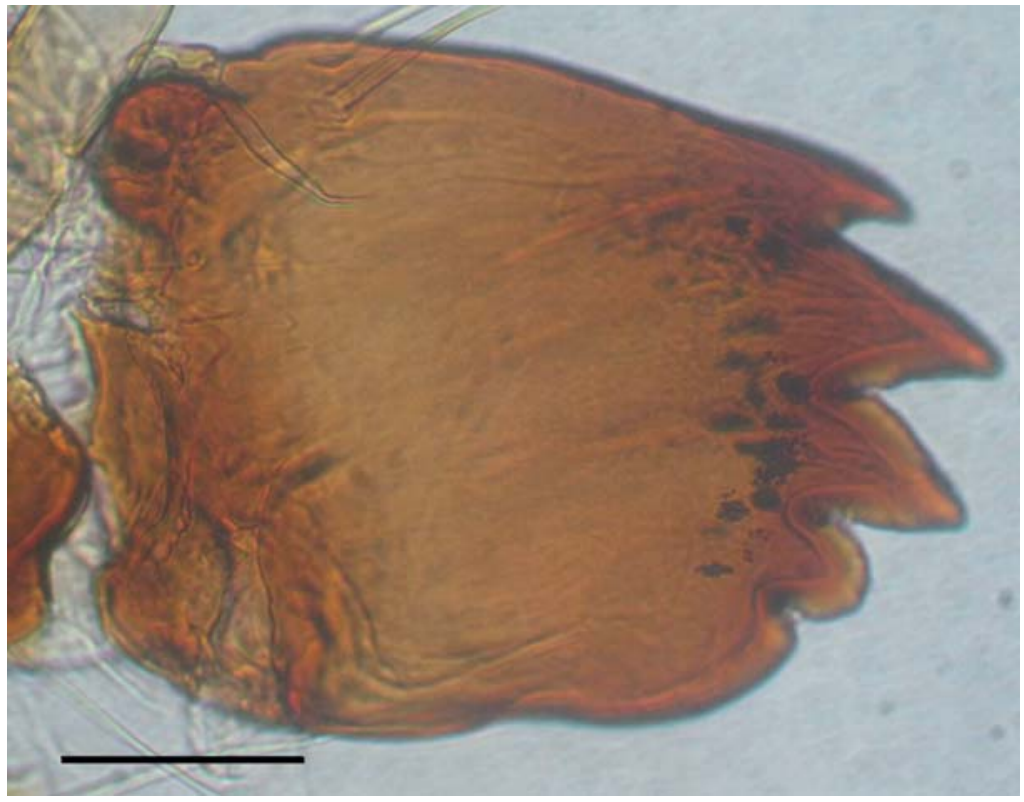

Figura 13. Larva de Grapholita molesta. Mandíbula. Escala: 0,1 mm.

FigURE 13. Grapholita molesta larvae. Mandible. Scale: $0.1 \mathrm{~mm}$.

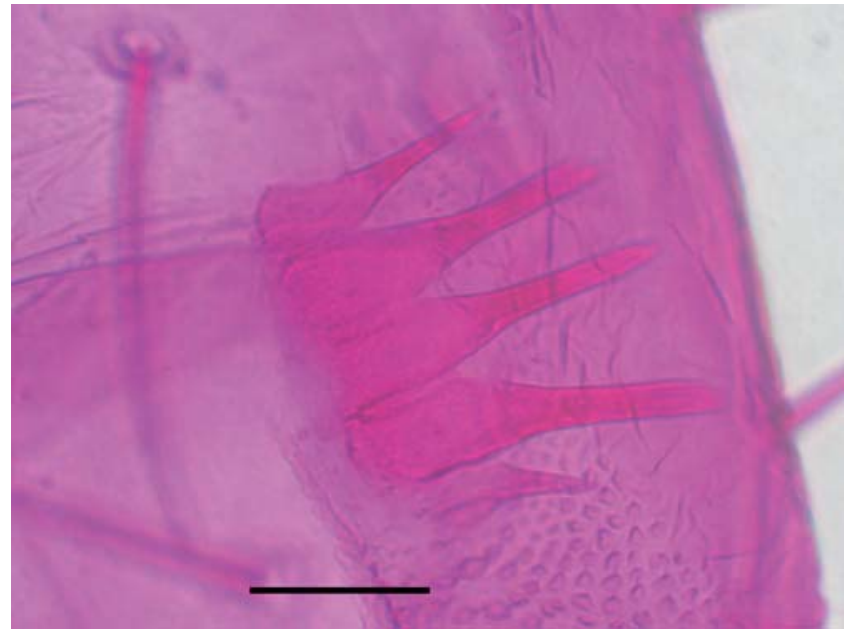

Figura 14. Larva de Grapholita molesta. Peine anal. Escala: 0,1 mm. Figure 14. Grapholita molesta larvae. Anal comb. Scale: $0.1 \mathrm{~mm}$.

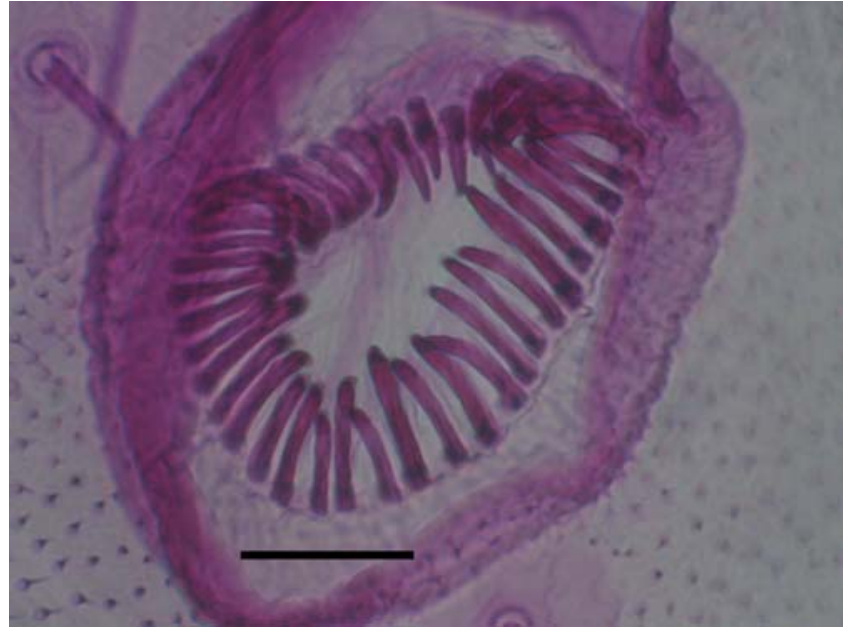

Figura 15. Larva de Grapholita molesta. Crochets. Escala: 0,1 mm. FIGURE 15. Grapholita molesta larvae. Crochets. Scale: $0.1 \mathrm{~mm}$. 


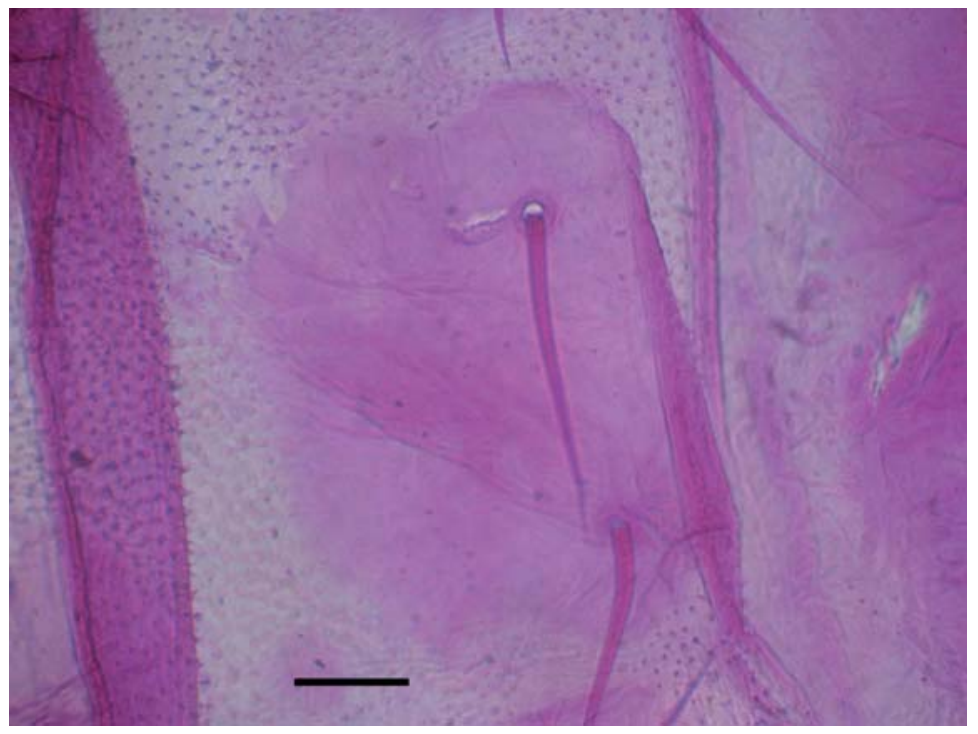

Figura 16. Larva de Grapholita molesta. Detalle de pináculo de D2 en A9. Escala: 0,1 mm.

Figure 16. Grapholita molesta larvae. Pinnacle detail D2 on A9. Scale: $0.1 \mathrm{~mm}$.

\section{Lobesia botrana (Denis \& Schiffermüller)}

(Figuras 17 - 24)

Diagnosis: Larva de color general del cuerpo variable, de color cremoso, verde claro o de tonalidad oscura, en algunos ejemplares con pináculos destacados de tonalidad clara, longitud máxima de $13 \mathrm{~mm}$. Cabeza de color castaño claro, con banda oscura, levemente insinuada a semicompleta, en la zona de la gena; zona estematal con mancha negra; antenas con banda oscura en el segundo segmento. Labro de forma bilobulada con 12 setas en su cara externa y 6 en su cara interna, espínulas de la epifaringe poco densas, ubicadas desde el centro hacia la base del labro; mandíbulas fuertemente quitinizadas con 5 dientes, siendo los tres marginales más agudos. Espinerete corto de forma subcilíndrica, curvo y de ápice redondeado; palpos labiales cilíndricos y más cortos que el largo respecto del espinerete. Protórax con placa torácica destacada, de color castaño, en ocasiones con el borde de la zona basal más oscura, surco medio dorsal presente y notable, de textura microreticulada; espiráculo de forma oblonga. Patas bien quitinizadas, fémur, tibia y tarso, por lo general, de color castaño oscuro, garra del tarso simple. Abdomen con espiráculos de forma circular, siendo el de A8 de diámetro mayor que los precedentes y separado del pináculo, a una distancia levemente mayor que su propio diámetro. Espuripedios presentes con crochets dispuestos en bandas biordinales. Placa anal bien diferenciada, de color castaño claro, de textura levemente microreticulada en zona central; peine anal presente, fuertemente quitinizado, compuesto de 5 a 7 dientes, unidos en la base y ligeramente truncos al ápice. Tegumento del cuerpo, cubierto densamente de micro procesos de forma circular, que presenta una pequeña espina distal.

Antena: Primer segmento anular y corto. Segundo segmento ensanchado, cilíndrico, bien quitinizado, con una textura microreticulada, presenta un sensilo campaniforme poco notorio, ubicado cerca de la base. Posee además cinco sensilos: dos tricodeos, siendo el más pequeño, mayor a la mitad del largo del segmento, ubicado en la mitad superior y tres sensilos basicónicos, siendo uno de ellos igual o mayor en largo respecto al tercer segmento. Tercer segmento cilíndrico, corto y quitinizado, cerca de tres veces menor respecto del largo del segundo, posee además tres sensilos, uno estilocónico y dos basicónicos.

\section{Quetotaxia del último estado:}

Cabeza: 6 estemas de forma semicircular. Estema 5 desplazado hacia la zona anterior; seta S1 postero a estema 3; S2 posteroventral a estema 1; seta S3 ubicada posteroventral a S2; seta SS2 ubicada posteroventral a estema 5; seta SS3 posteroventral a SS2; seta SS1 anteroventral a SS2; A1, A2, A3 y L1 dispuestas en forma angular, no alineadas; AF1, AFa y AF2 presentes; V1, V2, Va y V3 presentes.

Tórax: Protórax con placa torácica bien destacada, con textura microreticulada, a modo de celditas alargadas, surco 
medio dorsal presente. Seta SD1 puede presentarse más cercana a SD2, equidistante o cercana a XD2. Seta MXD1 por lo general, más cerca de D1 que a D2. Grupo de setas $\mathrm{L}$ inserto en pináculo de forma oblonga, anteroventral al espiráculo, L2 no alineada con respecto a L1 y L3. Grupo de setas SV bisetoso ubicado sobre pináculo ventral al del grupo L. V1 ubicada sobre pináculo de forma circular. Mesotórax y metatórax con grupo de setas D bisetoso, con ambas setas ubicadas sobre un mismo pináculo, D1 posterodorsal a D2. Grupo SD bisetoso con ambas setas ubicadas sobre un mismo pináculo. MSD1 y MSD2 en pináculos separados. L2 y L1 ubicadas sobre pináculo de forma semicircular y anteroventral a L3. Grupo SV unisetoso en pináculo de forma semicircular y ventral al de L3. V1 ubicado en la base de la coxa.

Abdomen: A1 y A2 con grupo D bisetoso, con ambas setas ubicadas sobre pináculos separados, de forma semicircular, D1 antero dorsal a D2. Grupo SD bisetoso con SD2 separado a SD1. Setas L1 y L2 sobre pináculo de forma semicircular y ubicado anteroventral a espiráculo, L3 posteroventral a L1 y L2. Grupo SV trisetoso. V1 ubicado sobre pináculo de forma semicircular. A3-A6, similar a A1 y A2 pero con grupo SV, en pináculo que rodea la base del espuripedio. V1 ubicado en cara interna de espuripedio. A7 similar a A1 y A2 pero con grupo SV trisetoso, con setas dispuestas de forma subtriangular. A8 similar a A1 y A2, pero con seta SD1 ubicado antero al espiráculo, siendo su diámetro menor a la mitad del diámetro del pináculo y grupo SV bisetoso. En A9 seta D1 sobre un mismo pináculo que SD1; D2 sobre pináculo, por lo general, de forma subtriangular. Grupo L trisetoso dispuesto sobre un único pináculo. Grupo SV bisetoso. V1 ubicado en pináculo de forma semicircular. A10 con placa anal bien diferenciada, con escasa microreticulación central, con 4 pares de setas, con SD1, D1 y SD2 formando un ángulo agudo. Grupo L trisetoso, ubicado sobre pináculo de forma ovoidal.

Variaciones intraespecíficas: Especie prácticamente estable en su quetotaxia. En un ejemplar se observó la fórmula del grupo SV, de la forma 2:2:3:2:2 y en segmento A8 la seta SD2 adyacente a pináculo de SD1. En segmento A9 se observó variadas formas de pináculo de setas D2, subtriangular, cordiforme e irregular.

Hospederos: Especie que de acuerdo a la literatura registra un amplio rango de hospederos, de aproximadamente 27 familias botánicas, siendo su principal hospedero la vid vinífera (Vedette et. al 2003).

Material examinado: 15 preparaciones microscópicas, Alto Jahuel, provincia del Maipo, Región Metropolitana, 10 de marzo, 2008, Coll. D.E. Cepeda \& G.E. Cubillos, en Vitis vinifera (4 ejemplares de $5^{\circ}$ estado); Linderos, provincia del Maipo, Región Metropolitana, 28 de marzo, 2008, Coll. D.E. Cepeda \& G.E. Cubillos, en Vitis vinifera (5 ejemplares de $5^{\circ}$ estado); Alto Jahuel, provincia del Maipo, Región Metropolitana, 28 de marzo, 2008, Coll. D.E. Cepeda \& G.E. Cubillos, en Vitis vinifera (5 ejemplares de $5^{\circ}$ estado y 1 ejemplar de $4^{\circ}$ estado).

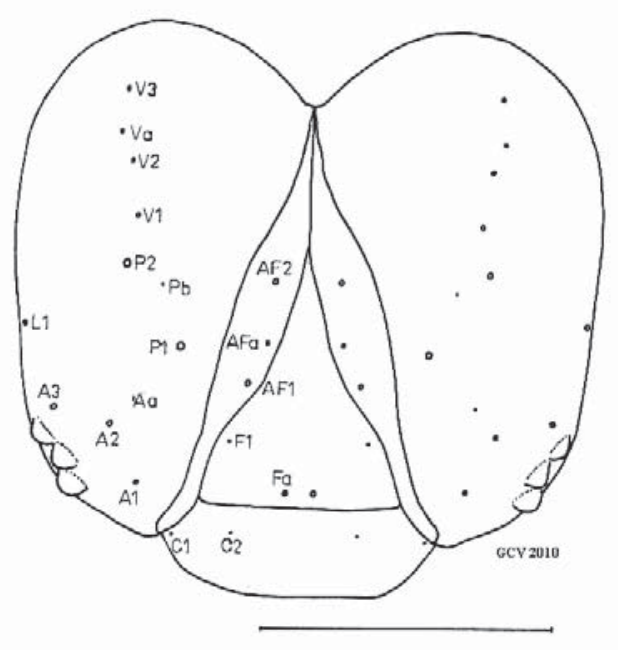

FiguRa 17. Larva de Lobesia botrana. Quetotaxia de cabeza en vista frontal. Escala: 0,5 mm.

Figure 17. Lobesia botrana larvae. Chaetotaxy of head in frontal view. Scale: $0.5 \mathrm{~mm}$. 


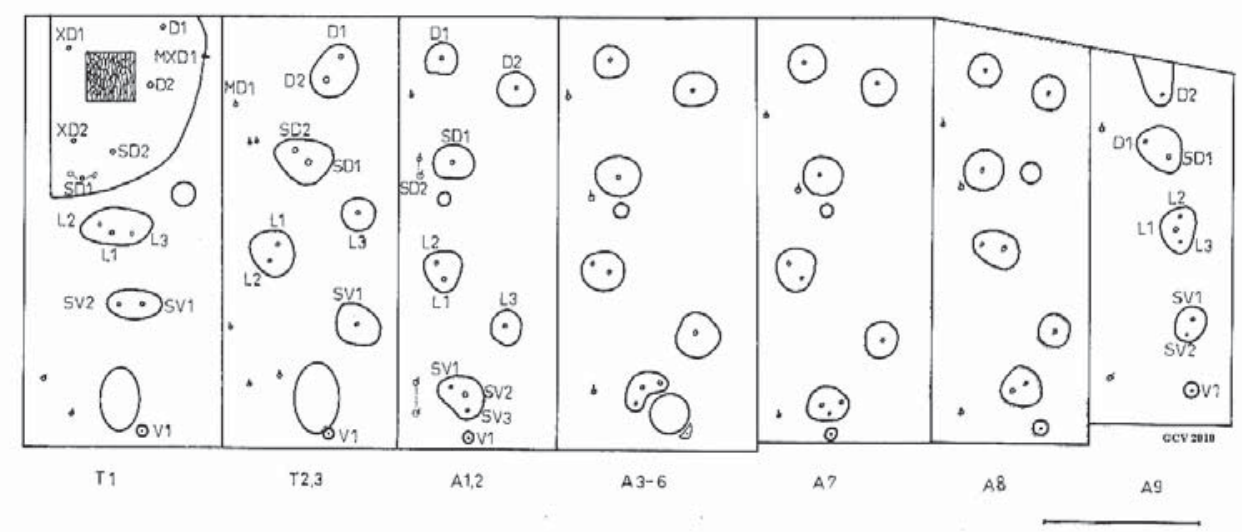

FiguRa 18. Larva de Lobesia botrana. Quetotaxia de tórax y abdomen en vista lateral. Escala: 0,5 mm. Figure 18. Lobesia botrana larvae. Chaetotaxy of thorax and abdomen in lateral view. Scale: $0.5 \mathrm{~mm}$.

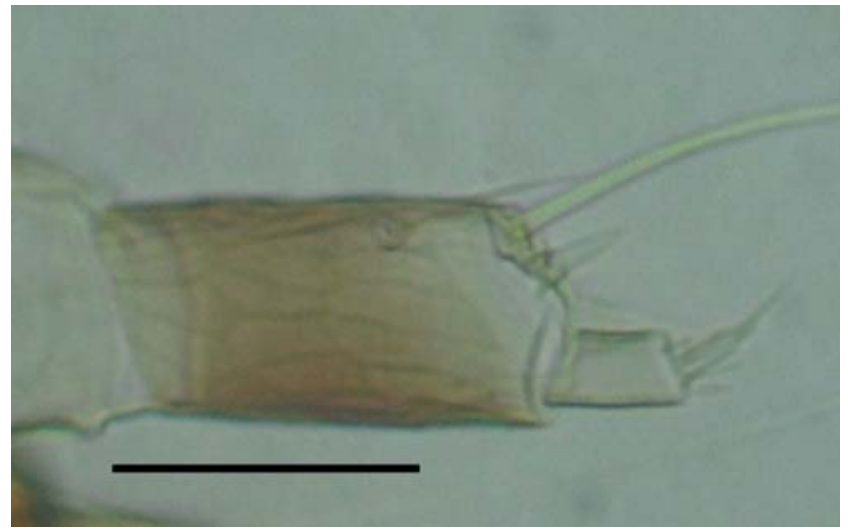

Figura 19. Larva de Lobesia botrana. Antena. Escala: 0,1 mm. Figure 19. Lobesia botrana larvae. Antennae. Scale: $0.1 \mathrm{~mm}$.

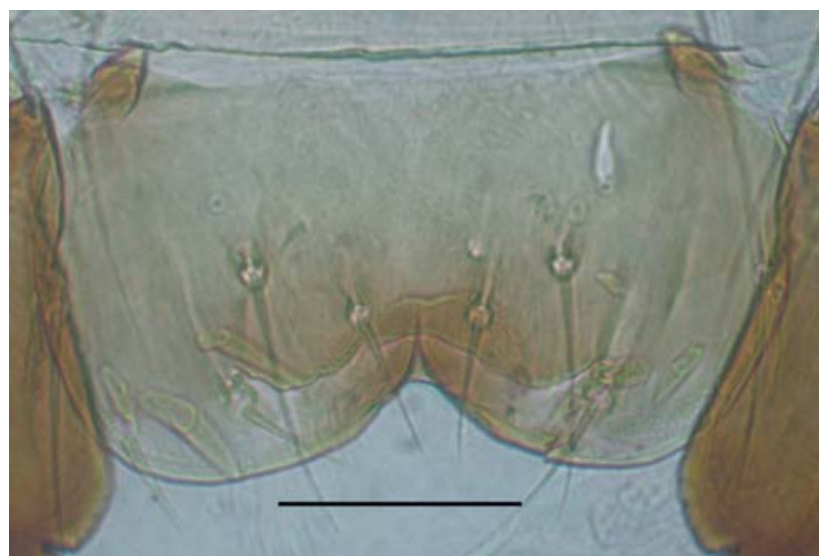

Figura 20. Larva de Lobesia botrana. Labro. Escala: $0,1 \mathrm{~mm}$. Figure 20. Lobesia botrana larvae. Labrum. Scale: $0.1 \mathrm{~mm}$. 


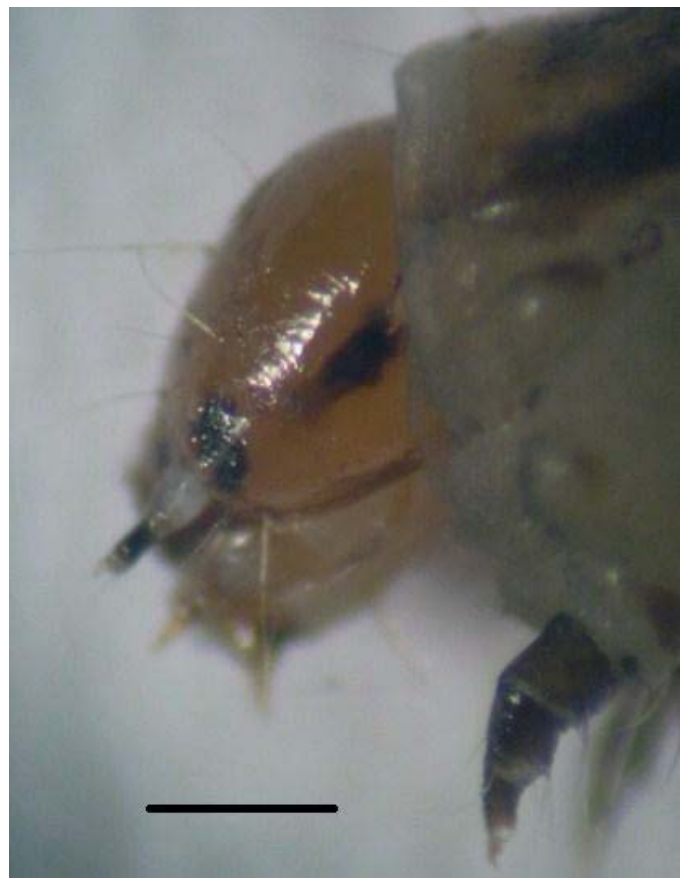

Figura 21. Larva de Lobesia botrana. Detalle de cabeza en vista lateral. Escala: 0,5 mm.

Figure 21. Lobesia botrana larvae. Detail of head in lateral view. Scale: $0.5 \mathrm{~mm}$.

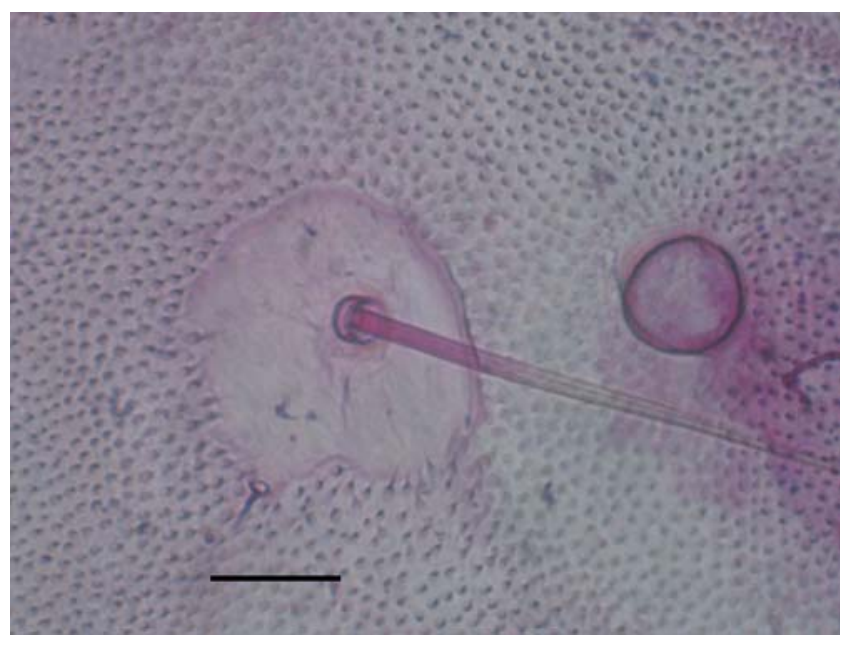

FIgURA 22. Larva de Lobesia botrana. Detalle de SD1, SD2 y espiráculo en A8. Escala: 0,1 mm.

Figure 22. Lobesia botrana larvae. Detail of SD1, SD2 and spiracle in A8. Scale: $0.1 \mathrm{~mm}$.

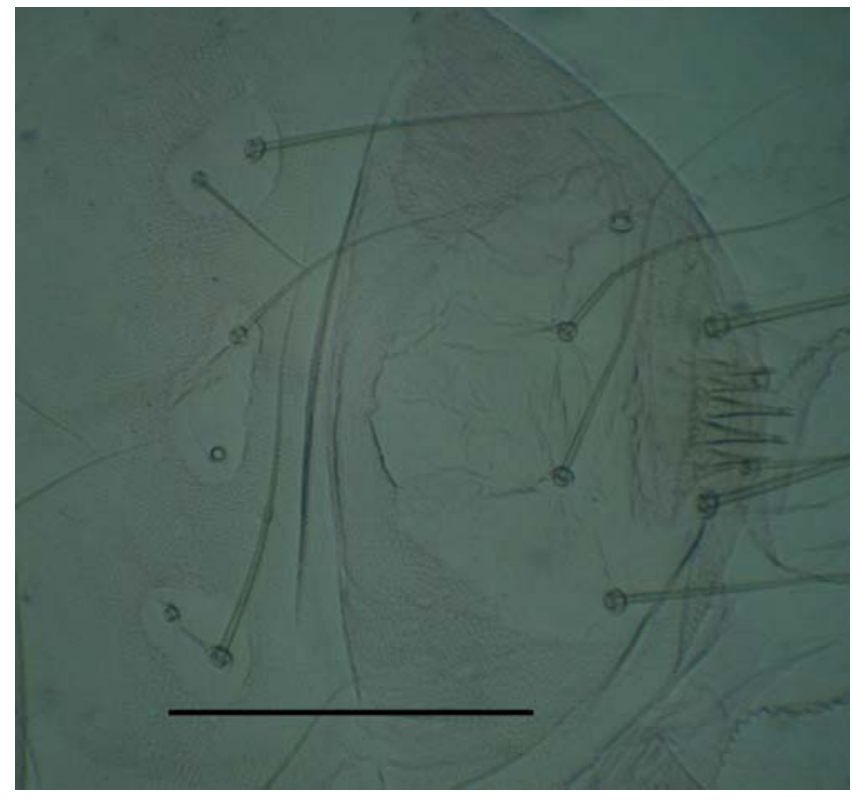

FIgURA 23. Larva de Lobesia botrana. Detalle de A9 y A10 en vista dorsal. Escala: 0,5 mm.

FIgURE 23. Lobesia botrana larvae. Detail A9 and A10 in dorsal view. Scale: $0.5 \mathrm{~mm}$. 


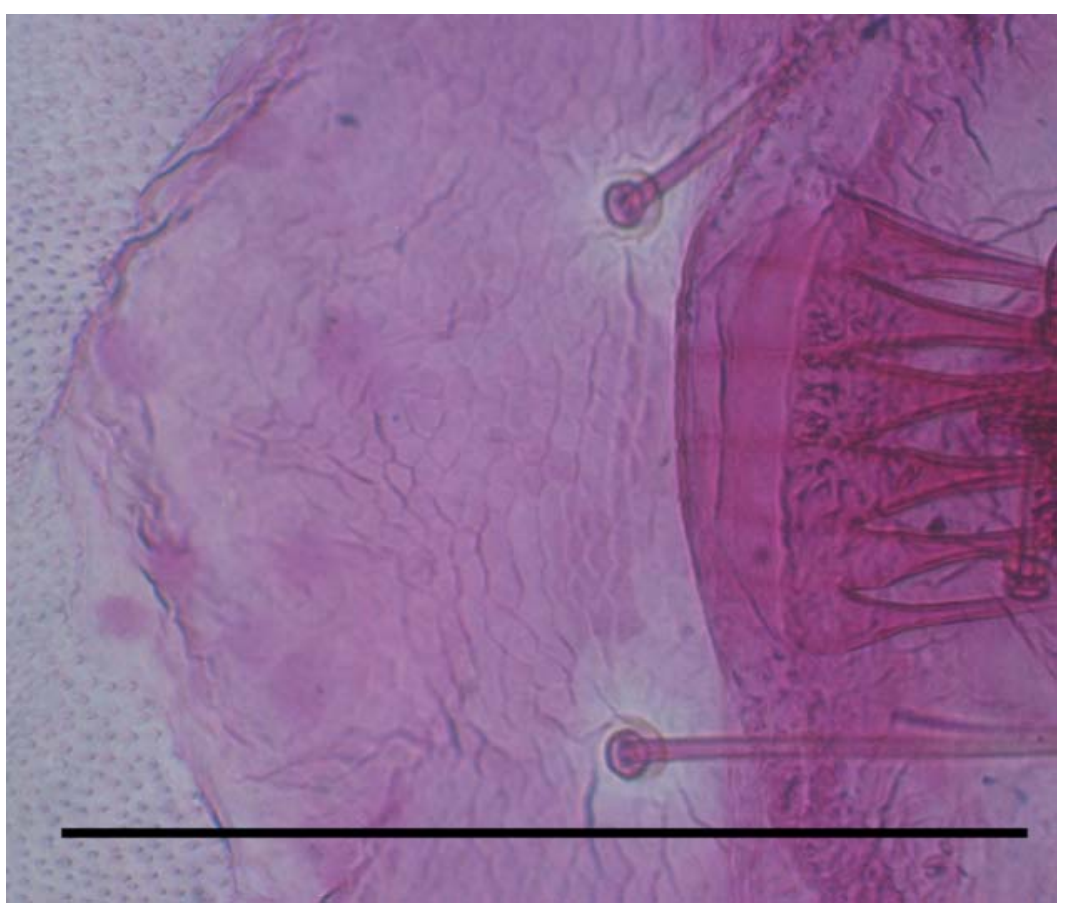

FIgURA 24. Larva de Lobesia botrana. Reticulación en placa anal. Escala: 0,5 mm.

FIGURE 24. Lobesia botrana larvae. Reticulation retail of anal plate. Scale: $0.5 \mathrm{~mm}$.

\section{Chileulia stalactitis (Meyrick)}

(Figuras 25 - 32)

Diagnosis: Larva de color general del cuerpo verde claro, con una notable franja dorsal longitudinal, de color rojiza, longitud máxima de $16 \mathrm{~mm}$. Cabeza de color castaño claro, con una pequeña mancha de tonalidad oscura al inicio de la gena. Labro de forma bilobulada con una gran escotadura central, con 12 setas ubicadas en la superficie externa y 6 en la cara interna; espínulas de la epifaringe poco densas, variadas en tamaño y ubicadas desde el centro hacia la base del labro. Mandíbulas fuertemente quitinizadas con 5 dientes, siendo 3 de forma prominente y agudos. Espinerete de forma subcilíndrica y alargado; palpos labiales cilíndricos y menor a la mitad del largo con respecto al espinerete. Protórax con placa torácica destacada, sin reticulación, de color similar al resto del cuerpo, con pequeñas manchas dispersas, de tonalidad oscura, con surco medio dorsal presente y destacado; espiráculo de forma ovoidal. Patas quitinizadas, de color similar al resto del cuerpo y con garra del tarso simple. Abdomen con espiráculos de forma circular, que se encuentran rodeados por un destacado anillo libre de microprocesos; siendo el de A8 de tamaño mayor en diámetro que los precedentes y separado cerca de un cuarto de su diámetro del pináculo. Espuripedios con crochets dispuestos en bandas biordinales. Placa anal bien diferenciada, de color similar al resto del cuerpo; peine anal presente, fuertemente quitinizado compuesto de 4 a 6 dientes. Tegumento del cuerpo cubierto de densos microprocesos espinosos, de base circular, alargados y agudos.

Antena: Primer segmento anular y corto. Segundo segmento ensanchado, cilíndrico, presenta un destacado sensilo campaniforme ubicado cerca de la base. Posee además cinco sensilos: dos tricodeos, siendo el más pequeño la mitad del largo del segmento, ubicado en la parte superior y tres sensilos basicónicos, siendo uno de ellos subigual en largo respecto al tercer segmento. Tercer segmento cilíndrico, corto y alongado, menor a la mitad del largo respecto del segundo, presenta además tres sensilos, uno estilocónico, el cual es mayor en largo respecto al segmento, y dos basicónicos.

\section{Quetotaxia del último estado:}

Cabeza: 6 estemas de forma semicircular. Estema 5 desplazado hacia la zona anterior de la cabeza; seta S1 ubicada ventral de estema 2; S2 ubicada posteroventral a estema 1; seta S3 ubicada ligeramente posteroventral a seta S2; la banda oscura de la gena entre S2 y S3; seta SS2 ubicada anteroventral a estema 6; seta SS3 ubicada ligeramente posteroventral a SS2; SS1 ubicada anteroventral a SS3; A1, A2 y A3 ubicadas en ángulo obtuso; AF1, AFa y 


\section{AF2 presentes; V1, V2, Va y V3 presentes.}

Tórax: Protórax con placa torácica bien destacada, de textura lisa, surco medio dorsal presente. SD1 más cerca a SD2 que a XD2, la distancia de SD1 a XD2, es mayor o casi el doble que a SD2. Seta MXD1 más cerca de D2 que a D1. Grupo de setas L, con L1 no alineada respecto a L2 y L3, inserto en pináculo de forma oblonga, anteroventral al espiráculo, el cual es de forma ovoidal. Grupo de setas SV bisetoso, ubicado sobre pináculo ventral al del grupo L. V1 en pináculo de forma circular y separada de la coxa. Mesotórax y metatórax con grupo de setas D bisetoso, con ambas setas ubicadas sobre un mismo pináculo, D2 levemente anteroventral a D1. Grupo SD bisetoso, ubicadas en un mismo pináculo de forma ovoidal, SD2 dorsal a SD1. L2 y L1 ubicadas sobre un mismo pináculo de forma oblonga, L2 anteroventral a L1, L3 ubicada sobre pináculo de forma circular y posterodorsal a L1. Grupo SV unisetoso sobre pináculo de forma circular y ubicada de forma posteroventral al de L3. V1 ubicado en la base de la coxa.

Abdomen: A1 y A2 con grupo D bisetoso, con ambas setas ubicadas sobre pináculos separados, D1 anterodorsal a D2. Grupo SD bisetoso, SD1 dorsal a espiráculo y ventral con D1, SD2 en un mismo pináculo o separado a SD1 en A1; en cambio en A2, SD2 siempre se encuentra separada. Setas L1 y L2 sobre un mismo pináculo ubicado anterodorsal a L3. Grupo SV trisetoso, ubicado en un mismo pináculo. V1 ubicado sobre pináculo de forma circular. A3-A6 similar a $\mathrm{A} 2$, pero con grupo $\mathrm{SV}$ sobre pináculo reniforme, ubicado en la base del espuripedio. A7 similar a A2, pero con SV bisetoso en pináculo de forma oblonga. A8 similar a A2, pero con SD bisetoso y ambas en un mismo pináculo, siendo el diámetro del espiráculo cerca de la mitad del diámetro del pináculo y con grupo SV bisetoso. En A9 seta D1 en pináculo separado a SD1, D2 ubicada sobre un gran pináculo de forma subtriangular. Grupo L trisetoso dispuesto sobre un mismo pináculo y con grupo SV bisetoso. V1 ubicado sobre pináculo de forma circular. A10 con placa anal bien diferenciada, con 4 pares de setas, con SD1, D1 y SD2 formando un ángulo agudo; grupo L trisetoso.

Variaciones intraespecíficas: En un ejemplar en segmento T1, la SV es monosetosa a un sólo lado. En segmento A1, SD2 está presente en un mismo pináculo y separado a SD1 en el mismo segmento. En un ejemplar se observó que en segmento A7 el grupo SV es trisetoso en ambos lados.

Hospederos: Esta especie ha sido reportada para los siguientes: Cotoneaster sp., Prunus cerasus, Prunus domestica, Vitis vinifera (González 1983); Thuja sp. (Prado 1988); Citrus sinensis, Prosopis tamarugo (Powell 1986); Austrocedrus chilensis (Brown \& Passoa 1998).

Material examinado: 4 preparaciones microscópicas, Las Condes, provincia de Santiago, Región Metropolitana, 9 de agosto, 1981, Coll. R.H. González, crianza de laboratorio, en Cotoneaster sp. ( 1 ejemplar de $3^{\text {er }}$ estado); San Clemente, provincia de Talca, Región del Maule, 19 de febrero, 1991, Coll. S. Bozzolo, crianza de laboratorio, en Vitis vinifera (1 ejemplar de $5^{\circ}$ estado); San Felipe, provincia de San Felipe de Aconcagua, Región de Valparaíso, 21 noviembre, 1983, Coll. R.H. González, crianza de laboratorio, en Vitis vinifera (1 ejemplar de $3^{\text {er }}$ estado); igual localidad, 29 noviembre, 1983, Coll. M.A. Guerrero, crianza de laboratorio, en Vitis vinifera ( 1 ejemplar de $4^{\circ}$ estado). Un ejemplar $\partial^{\lambda}$, crianza de laboratorio, Las Condes, provincia de Santiago, Región Metropolitana, nacimiento, 15 de agosto de 1981, en Cotoneaster sp., Coll. R. H. González.

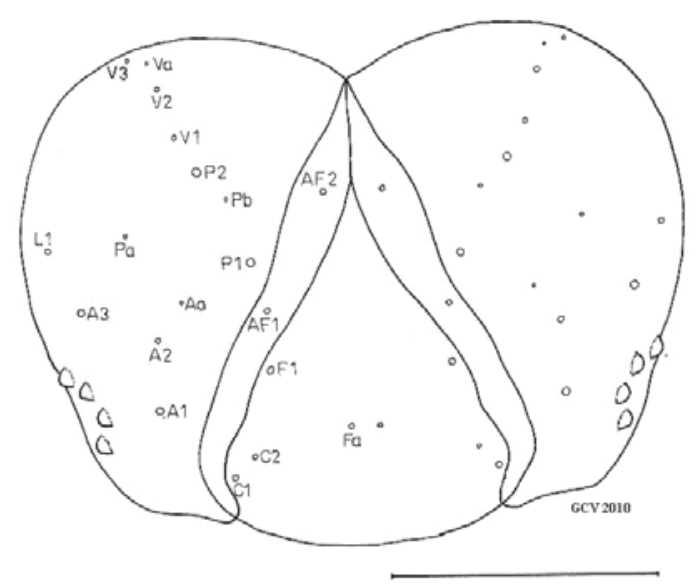

Figura 25. Larva de Chileulia stalactitis. Quetotaxia de cabeza en vista frontal. Escala: 0,5 mm.

FIgURE 25. Chileulia stalactitis larvae. Chaetotaxy of head in frontal view. Scale: $0.5 \mathrm{~mm}$. 


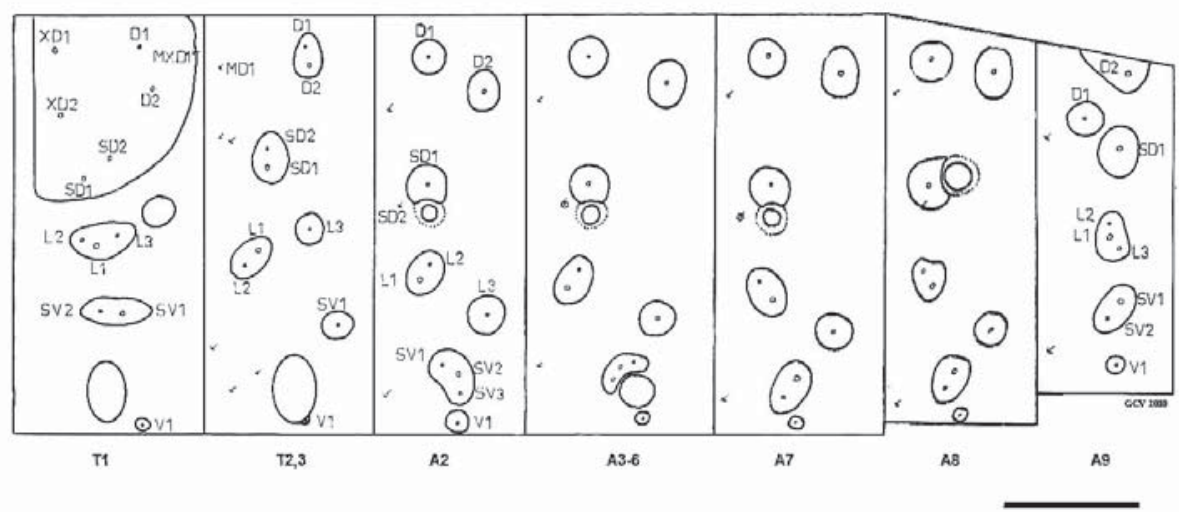

Figura 26. Larva de Chileulia stalactitis. Quetotaxia de tórax y abdomen en vista lateral. Escala: 0,5 mm.

FIgURE 26. Chileulia stalactitis larvae. Chaetotaxy of thorax and abdomen in lateral view. Scale: $0.5 \mathrm{~mm}$.

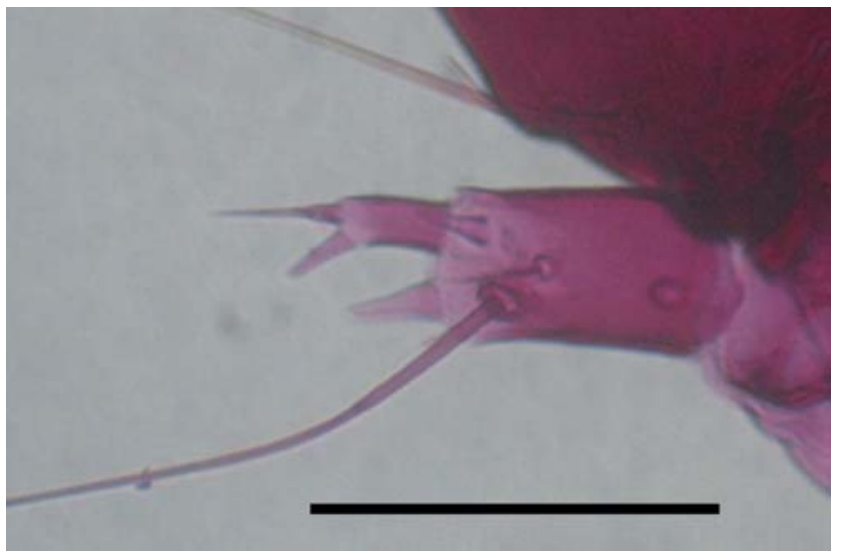

FIGURA 27. Larva de Chileulia stalactitis. Antena. Escala: 0,2 mm. Figure 27. Chileulia stalactitis larvae. Antennae. Scale: $0.2 \mathrm{~mm}$.

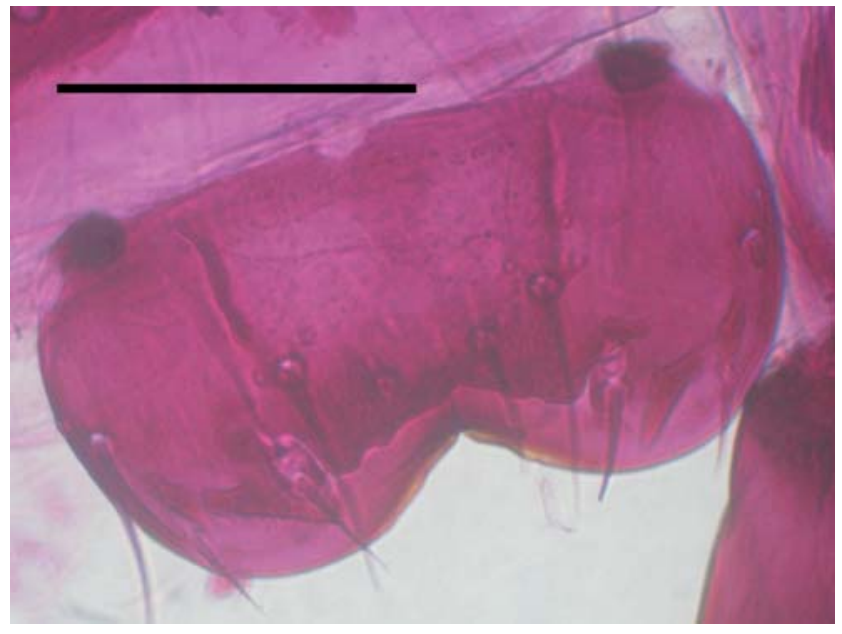

Figura 28. Larva de Chileulia stalactitis. Labro. Escala: 0,2 mm. FIgURE 28. Chileulia stalactitis larvae. Labrum. Scale: $0.2 \mathrm{~mm}$. 


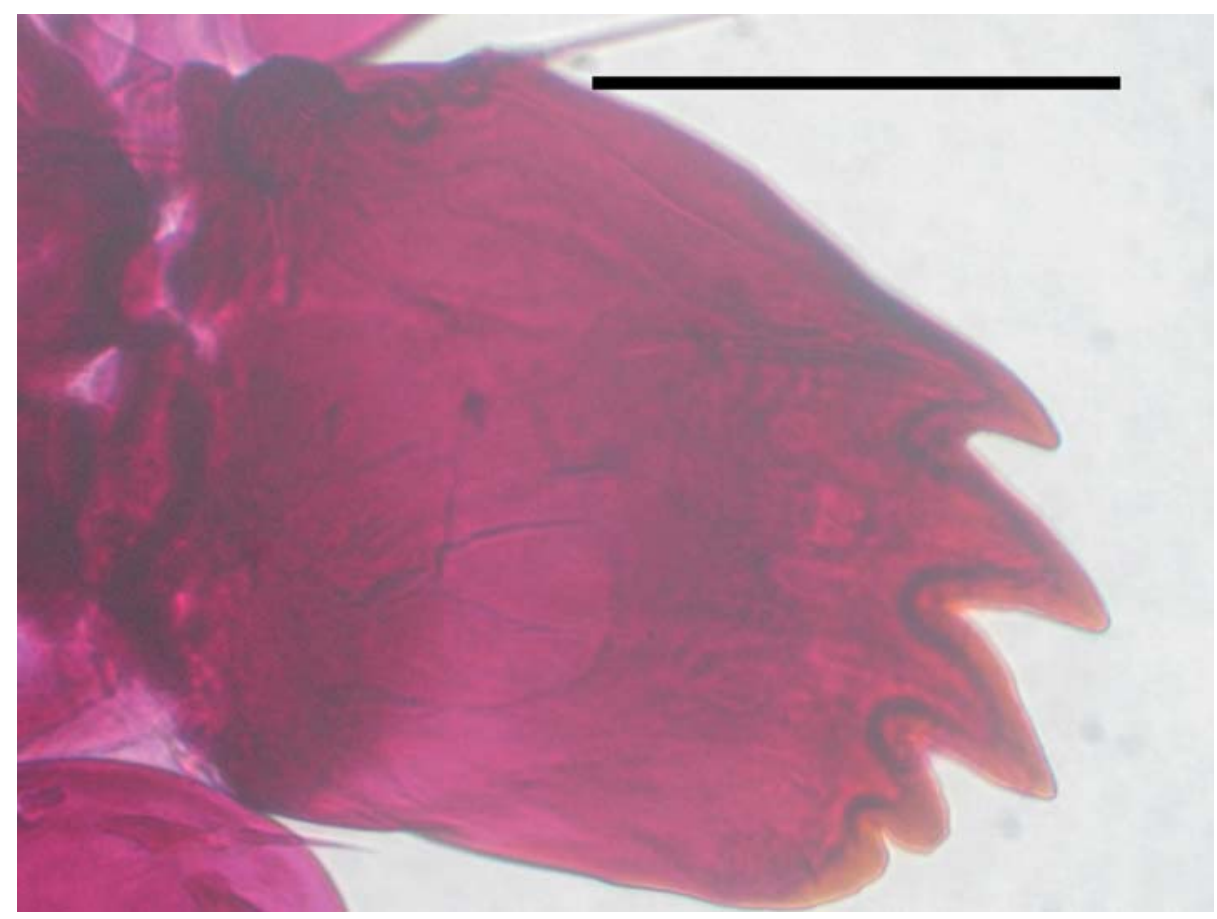

Figura 29. Larva de Chileulia stalactitis. Mandíbula. Escala: 0,2 mm.

Figure 29. Chileulia stalactitis larvae. Mandible. Scale: $0.2 \mathrm{~mm}$.

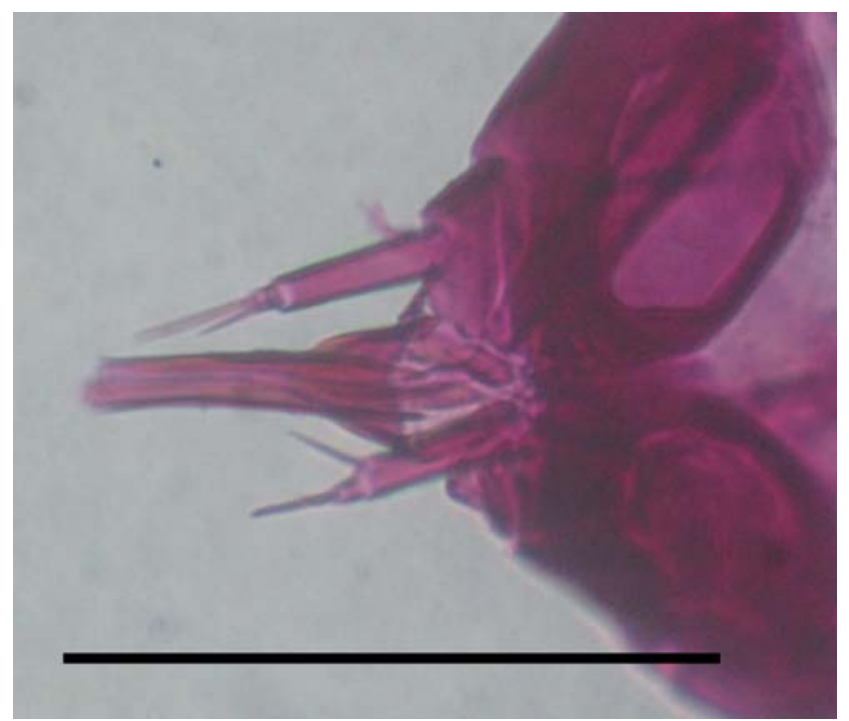

FIGURA 30. Larva de Chileulia stalactitis. Espinerete. Escala: 0,2 mm.

FIGURE 30. Chileulia stalactitis larvae. Spinneret. Scale: $0.2 \mathrm{~mm}$.

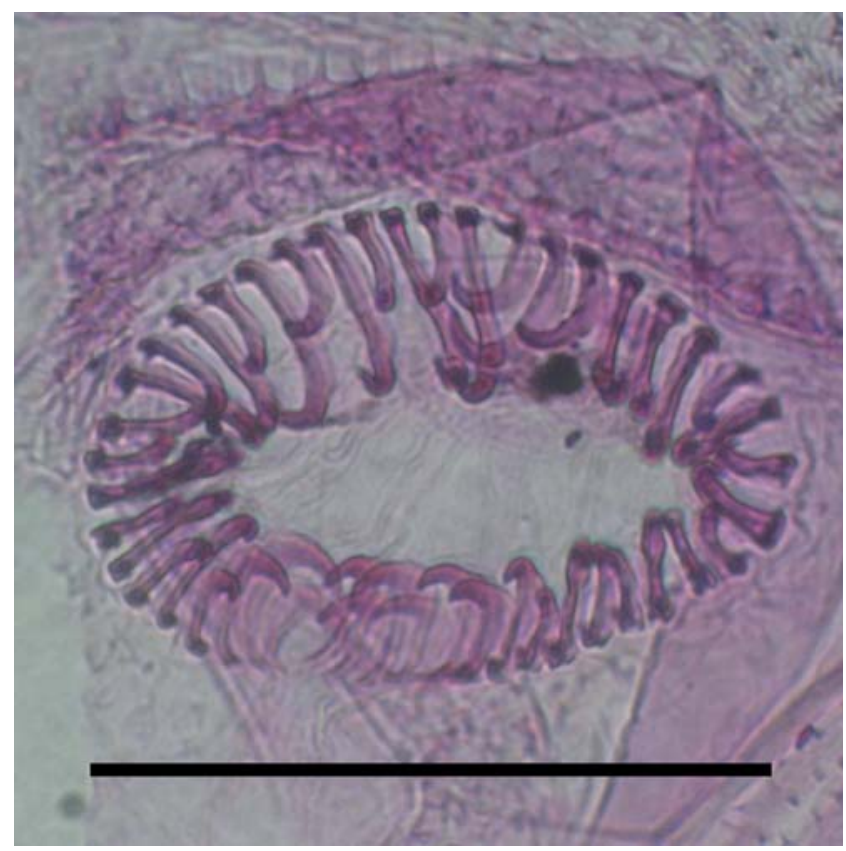

Figura 31. Larva de Chileulia stalactitis. Crochets. Escala: 0,2 mm.

Figure 31. Chileulia stalactitis larvae. Crochets. Scale: $0.2 \mathrm{~mm}$. 


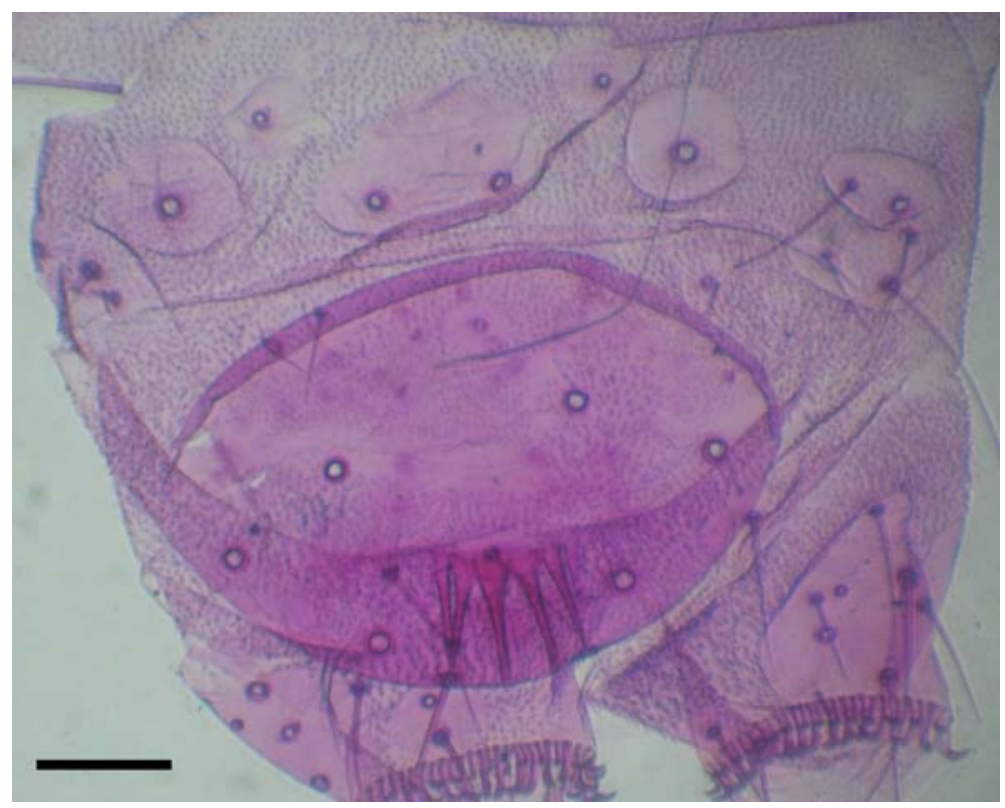

FIgura 32. Larva de Chileulia stalactitis. Detalle de A9 y A10 en vista dorsal. Escala: 0,2 mm.

Figure 32. Chileulia stalactitis larvae. Detail A9 and A10 in dorsal view. Scale: $0.2 \mathrm{~mm}$.

\section{Proeulia auraria (Clarke)}

(Figuras 33 - 40)

Diagnosis: Larva de color general del cuerpo verde claro, longitud máxima de $22 \mathrm{~mm}$. Cabeza de color castaño claro, con pequeñas manchas dispersas, de tonalidad oscura, con una notable franja de color negra, que recorre desde el borde de la gena hasta el seno occipital, de mayor a menor grosor; antenas con banda oscura incompleta en el primer segmento y completa en el segundo. Clípeo de tonalidad clara; labro de color oscuro y de forma bilobulada con una gran escotadura central, con 12 setas ubicadas en la superficie externa y 6 en la cara interna; espínulas de la epifaringe poco densas y alargadas, ubicadas desde el centro hacia la base del labro. Mandíbulas fuertemente quitinizadas, con 5 dientes, siendo por lo general 4 de forma aguda. Espinerete de forma subcilíndrico y levemente curvado; palpos labiales cilíndricos, alargados, subigual a la mitad del largo del espinerete. Protórax con placa torácica destacada, sin reticulación, de color similar al resto del cuerpo, con pequeñas manchas dispersas, de tonalidad oscura, con surco medio dorsal presente y destacado; espiráculo de forma circular. Patas quitinizadas, de color similar al resto del cuerpo y con garra del tarso simple. Abdomen con espiráculos de forma circular, siendo el de $\mathrm{A} 8$ de tamaño mayor en diámetro que los precedentes, con forma de media luna, prácticamente adyacente al pináculo. Espuripedios con crochets dispuestos en bandas biordinales. Placa anal bien diferenciada, de color similar al resto del cuerpo; peine anal presente, fuertemente quitinizado, compuesto de 7 a 9 dientes, unidos en la base, posteriormente separados, siendo los dientes laterales agudos. Tegumento del cuerpo cubierto de densos microprocesos espinosos.

Antena: Primer segmento anular, quitinoso y corto. Segundo segmento cilíndrico, alongado, quitinoso y con textura reticulada, presenta un sensilo campaniforme poco destacado, ubicado cerca de la base. Posee además, cinco sensilos: dos tricodeos, siendo el más pequeño menor a la mitad del largo respecto del segmento, ubicado en el tercio superior y tres sensilos basicónicos. Tercer segmento cilíndrico, alongado, menor a la mitad del largo respecto del segundo segmento. Además posee tres o cuatro sensilos, uno estilocónico y dos o tres basicónicos.

\section{Quetotaxia del último estado:}

Cabeza: 6 estemas de forma semicircular. Estema 5 desplazado hacia la zona anterior de la cabeza; seta S1 ubicada ventral a estema 2; S2 ubicada posteroventral a estema 1; seta S3 ubicada levemente posteroventral a seta S2; la banda oscura de la gena sobrepasa dorsalmente a S2 y en S3 ubicada al margen de la misma; seta SS2 ubicada anteroventral a estema 6; seta SS3 ubicada ligeramente posteroventral a SS2; SS1 ubicada anteroventral a SS3; A1, A2, A3 y L1 ubicadas en ángulo obtuso muy extendido; $\mathrm{AF} 1, \mathrm{AFa}$ y AF2 presentes; V1, V2, Va y V3 presentes. 
Tórax: Protórax con placa torácica bien destacada con textura lisa, surco medio dorsal presente. Seta SD1, por lo general, más cerca a SD2 que a XD2. Seta MXD1 cercana a seta D2. Grupo de setas L, inserto en pináculo de forma elíptica, anteroventral al espiráculo, el cual es de forma circular, L2, L1 y L3 alineadas. Grupo de setas SV bisetoso, ubicado sobre pináculo ventral al del grupo L. V1 ubicado en pináculo de forma circular. Mesotórax y metatórax con grupo de setas D bisetoso, con ambas setas ubicadas sobre un mismo pináculo, D1 dorsal a D2. Grupo SD bisetoso, ubicadas en un mismo pináculo, SD2 ligeramente antero dorsal a SD1. L2 y L1 ubicadas sobre un mismo pináculo de forma elíptica, L2 anteroventral a L1, L3 ubicada sobre pináculo de forma circular y posterodorsal a L1. Grupo SV unisetoso sobre pináculo de forma circular y ubicada de forma levemente posteroventral al de L3. V1 ubicada en la base de la coxa.

\begin{abstract}
Abdomen: A1 y A2 con grupo D bisetoso, con ambas setas ubicadas sobre pináculos separados, D1 anterodorsal a D2. Grupo SD bisetoso, dorsal a espiráculo y ventral con D1; en A1 seta SD2, por lo general, en un mismo pináculo que SD1, en cambio en A2 siempre separado. Setas L1 y L2 sobre pináculo ubicado anterodorsal a L3. Grupo SV trisetoso, ubicado en un mismo pináculo. V1 ubicado sobre un amplio pináculo de forma circular. A3-A6 similar a A1 y A2, pero con SD2 siempre separado a SD1. Grupo SV sobre pináculo reniforme, ubicado en la base del espuripedio. A7 similar a A1 y A2, pero con SD2 siempre en pináculo separado y SV trisetoso, dispuestas de forma subtriangular. A8 similar a A1 y A2, pero con SD bisetoso y, por lo general, SD2 en mismo pináculo que SD1, siendo el diámetro del espiráculo mayor a la mitad del diámetro del pináculo y grupo SV bisetoso. En A9 seta D1 sobre un mismo pináculo que SD1. D2 ubicada sobre un gran pináculo de forma subtriangular. Grupo L trisetoso, dispuesto sobre un mismo pináculo. Grupo SV bisetoso. V1 ubicado sobre pináculo de forma circular. A10 con placa anal bien diferenciada, con 4 pares de setas, con SD1, D1 y SD2 formando un ángulo agudo. Grupo L trisetoso.
\end{abstract}

Variaciones intraespecíficas: Especie estable en su quetotaxia. En un ejemplar, en segmento A10 la seta D1 estaba en pináculo separado a SD1, solo en un lado, carácter propio de los Tortricinae (MacKay 1962). En segmentos A1 y A8, en ocasiones la seta SD2 puede estar separada a SD1. En dos preparaciones es posible observar una leve reticulación central en la placa anal.

Hospederos: Han sido citados los siguientes: Aristolochia chilensis(Obraztsov 1964); Citrus sinensis, Malus domestica, Drymis winteri, Platanus orientalis, Prunus armeniaca, Pyrus communis, Vitis vinifera (Campos et al 1981); Luma sp. (Álvarez \& González 1982); Prunus domestica, Actinidia deliciosas, (González 1989); Myrtaceae (arbustos, sin identificar), Prunus avium, Platanus orientalis (Brown \& Passoa 1998); Prunus persicae, Juglans regia, Cryptocarya alba, Quillaja saponaria, Robinia pseudoacacia (González 2003). Nuevos antecedentes: Simmondsia chinensis, Cotoneaster sp., Cercis siliquastrum, Rosa sp., Nothofagus obliqua, Pittosporum tobira, Punica granatum, Buddleja davidii y Fuchsia magellanica.

Material examinado: 13 preparaciones microscópicas, Las Condes, provincia de Santiago, Región Metropolitana, 9 agosto, 1981, Coll. R.H. González, crianza de laboratorio, en Cotoneaster sp. ( 2 ejemplares de $5^{\circ}$ estado); Alto Jahuel, provincia del Maipo, Región Metropolitana, 3 octubre, 2008, Coll. D.E. Cepeda, en Vitis vinifera (5 ejemplares de $5^{\circ}$ estado y 1 de $4^{\circ}$ ); igual localidad, 6, 13 octubre; 15 diciembre, Coll. G.E. Cubillos; Graneros, provincia de Cachapoal, Región del Libertador General Bernardo O`Higgins, 23 octubre, 2008, Coll. D.E. Cepeda, crianza de laboratorio, en Prunus avium (1 ejemplar de $5^{\circ}$ estado); Curicó, provincia de Curicó, Región del Maule, 30 septiembre, 2008, Coll. D.E. Cepeda, crianza de laboratorio, en Vitis vinifera ( 1 ejemplar de $5^{\circ}$ estado); Ovalle, provincia de Limarí, Región de Coquimbo, 23 septiembre, 2010, Coll. J. Toro, crianza de laboratorio, en Punica granatum, (1 ejemplar de $5^{\circ}$ estado); Nancagua, provincia de Colchagua, Región del Libertador General Bernardo O'Higgins, 25 octubre, 2010, crianza de laboratorio, en Vitis vinifera (1 ejemplar de $5^{\circ}$ estado); Los Niches, provincia de Curicó, Región del Maule, 31 octubre, 2010, Coll. G.E. Cubillos, crianza de laboratorio, en Buddleja davidii (1 ejemplar de $5^{\circ}$ estado). Cuatro ejemplares + , crianza de laboratorio, Vitacura, provincia de Santiago, Región Metropolitana, adulto 18 enero de 1970, en Cercis siliquastrum, Coll. R.H. González; un ejemplar + , crianza de laboratorio, Las Condes, provincia de Santiago, Región Metropolitana, adulto 10-13 septiembre 1981, en Cotoneaster sp., Coll. R.H. González; un ejemplar $\widehat{\jmath}$, crianza de laboratorio, Las Condes, provincia de Santiago, Región Metropolitana, adulto 22 octubre 1982, en Rosa sp., Coll. R.H. González; un ejemplar $\hat{\partial}$, crianza de laboratorio, Curacaví, provincia de Melipilla, Región Metropolitana, adulto enero de 1986, en Sidmmondsia chinensis, Coll. R.H. González; un ejemplar +, crianza de laboratorio, Los Niches, provincia de Curicó, Región del Maule, pupa 12 marzo de 2003, adulto 24 marzo, en Nothofagus obliqua, Coll. D.E. Cepeda; un ejemplar $\hat{\sigma}^{\text {, }}$, crianza de laboratorio, igual localidad, larva de $5^{\circ}$ estado, 28 noviembre 2008, pupa 18 diciembre, adulto 4 enero de 2009, en Pittosporum tobira, Coll. D.E. Cepeda; un ejemplar $\widehat{\text { ô, }}$ crianza de laboratorio, igual localidad, larva de $5^{\circ}$ estado, 31 octubre, pupa 17 noviembre, adulto 25 noviembre de 2010, en Fuchsia magellanica, Coll. D.E. Cepeda. 


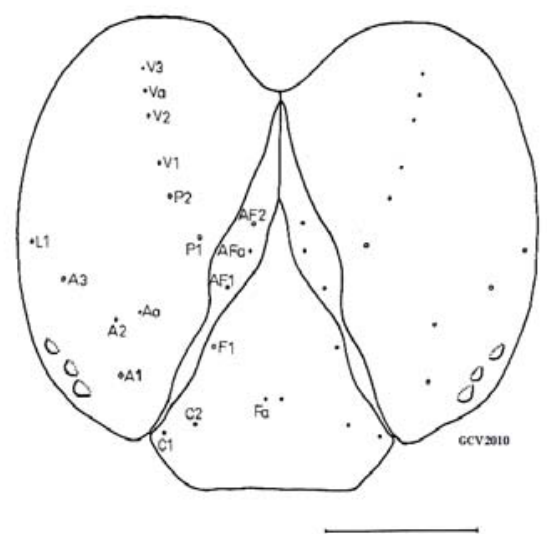

Figura 33. Larva de Proeulia auraria. Quetotaxia de cabeza en vista frontal. Escala: 0,5 mm.

Figure 33. Proeulia auraria larvae. Chaetotaxy of head in frontal view. Scale: $0.5 \mathrm{~mm}$

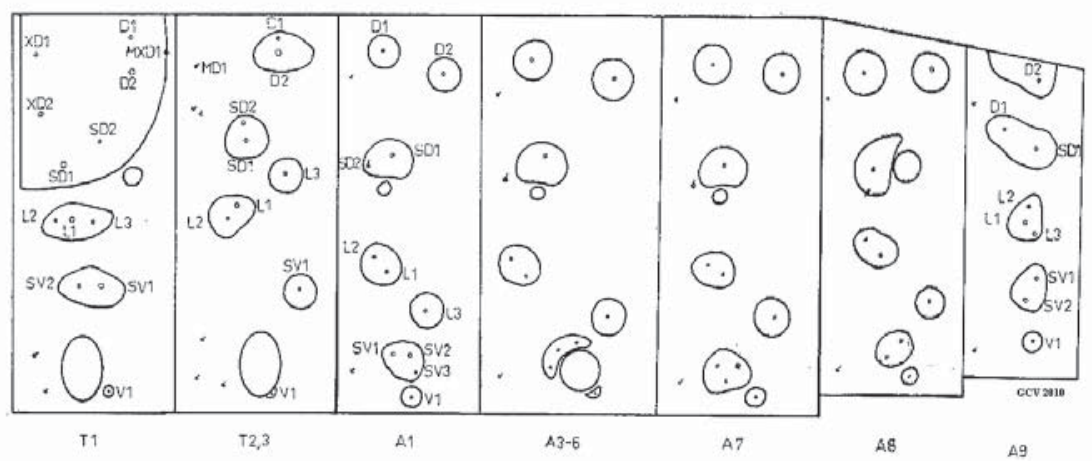

Figura 34. Larva de Proeulia auraria. Quetotaxia de tórax y abdomen en vista lateral. Escala: 0,5 mm.

Figure 34. Proeulia auraria larvae. Chaetotaxy of thorax and abdomen in lateral view. Scale: $0.5 \mathrm{~mm}$.

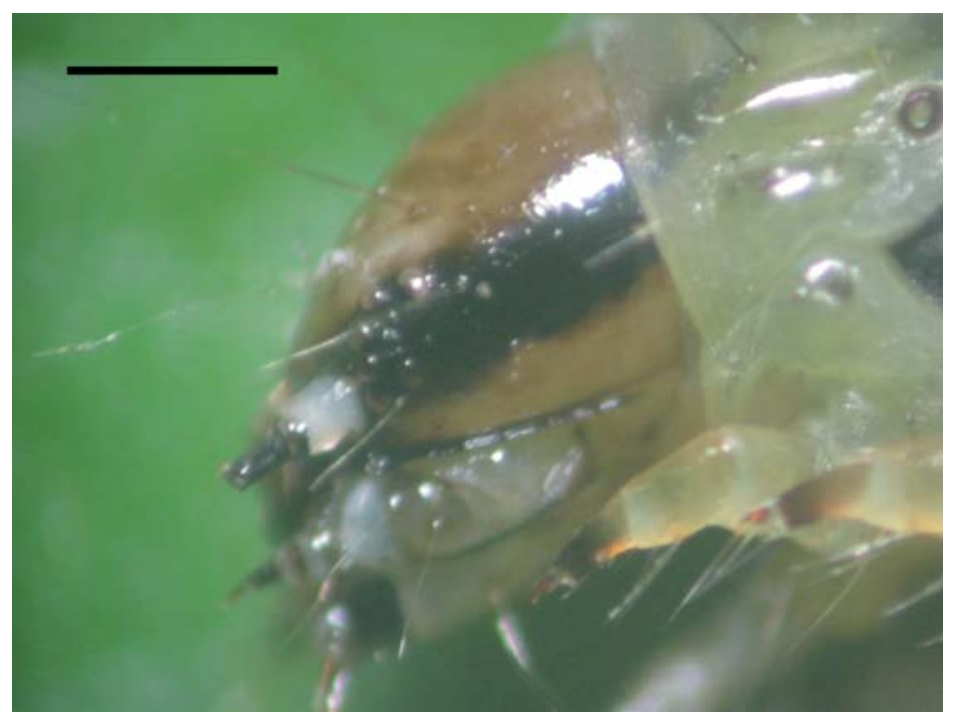

Figura 35. Larva de Proeulia auraria. Cabeza en vista lateral. Escala: 0,5 mm.

Figure 35. Proeulia auraria larvae. Head in lateral view. Scale: $0.5 \mathrm{~mm}$. 


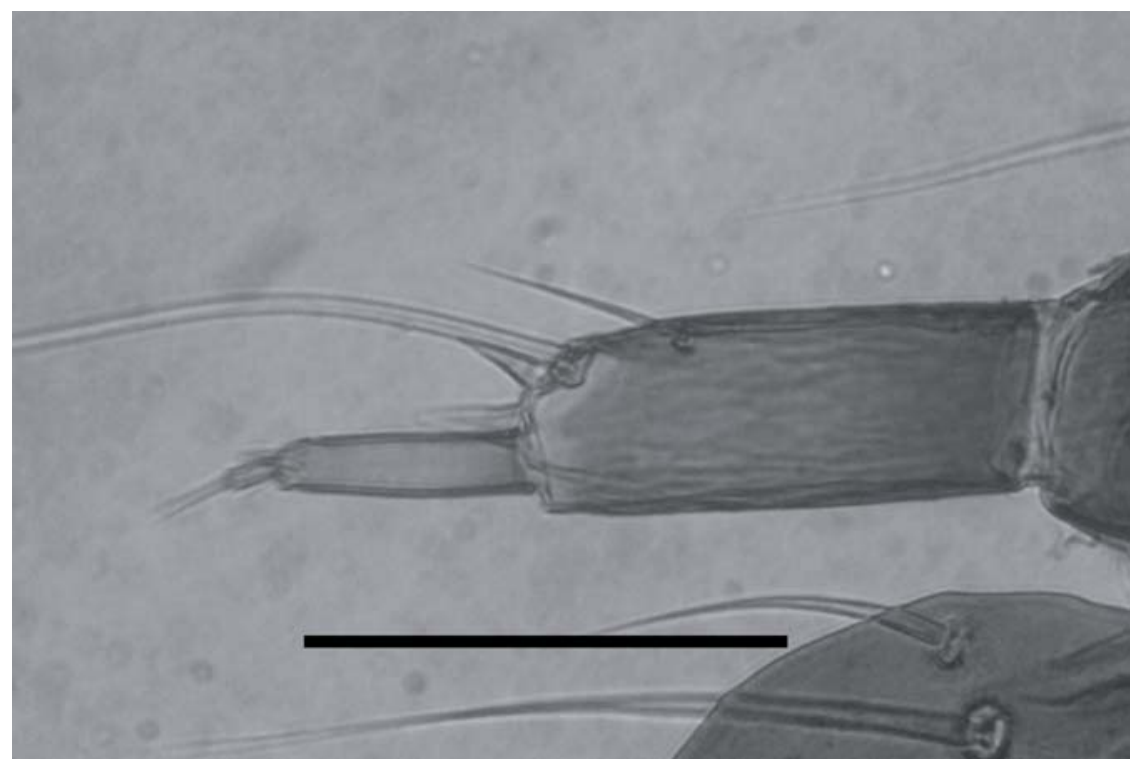

Figura 36. Larva de Proeulia auraria. Antena. Escala: $0,5 \mathrm{~mm}$.

FIgURE 36. Proeulia auraria larvae. Antennae. Scale: $0.5 \mathrm{~mm}$.

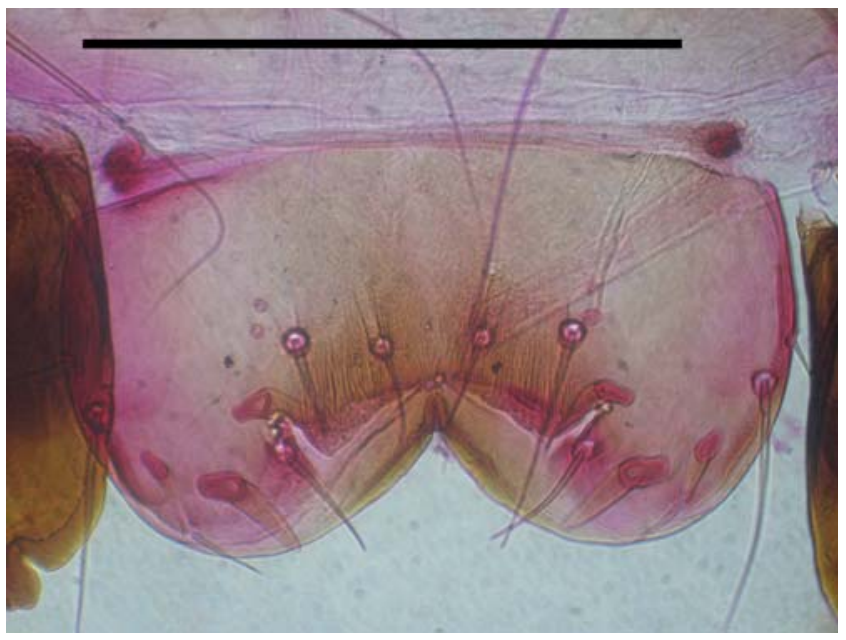

Figura 37. Larva de Proeulia auraria. Labro. Escala: $0,5 \mathrm{~mm}$.

Figure 37. Proeulia auraria larvae. Labrum. Scale: $0.5 \mathrm{~mm}$.

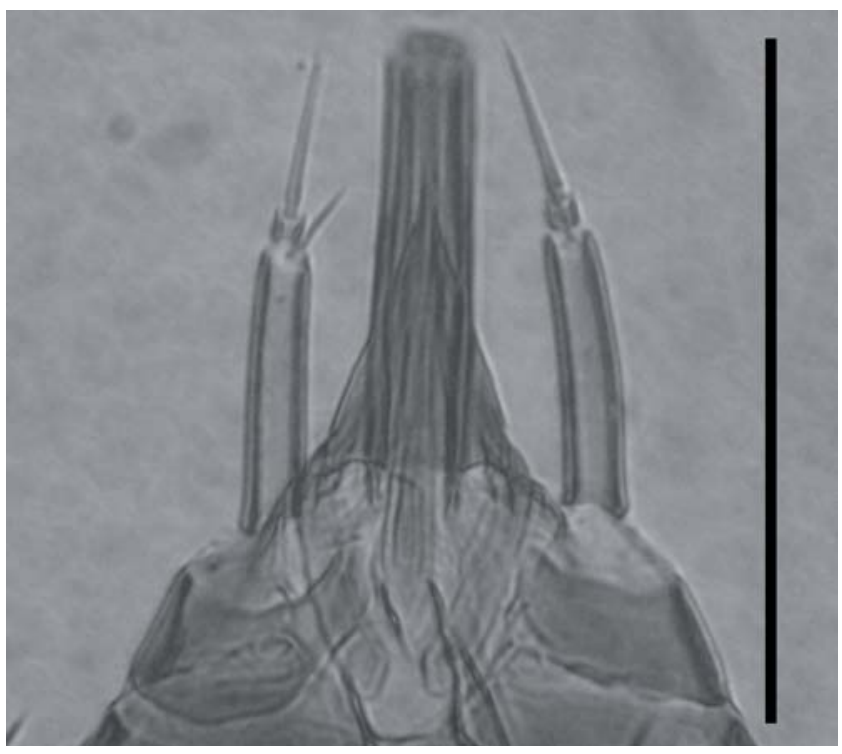

Figura 38. Larva de Proeulia auraria. Espinerete. Escala: 0,25 $\mathrm{mm}$.

Figure 38. Proeulia auraria larvae. Spinneret. Scale: $0.25 \mathrm{~mm}$. 


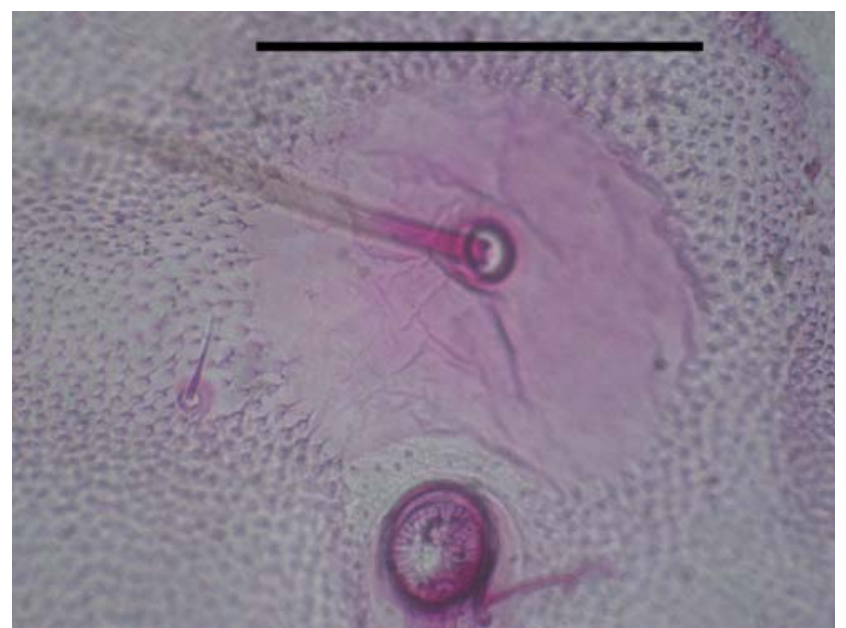

Figura 39. Larva de Proeulia auraria. Detalle de SD1, SD2 y espiráculo en A3. Escala: 0,25 mm.

FIgURE 39. Proeulia auraria larvae. Detail SD1, SD2 and spiracle A3. Scale: $0.25 \mathrm{~mm}$.

\section{Proeulia chrysopteris (Butler)}

(Figuras 41 - 48)

Diagnosis: Larva de color general del cuerpo verde claro, longitud máxima de $26 \mathrm{~mm}$. Cabeza de color verde amarillento; área interna de zona estematal con mancha de color negro; antenas de tonalidad castaño claro en segundo y tercer segmento. Labro bicolor con mancha en forma de $\mathrm{V}$ en su parte central, forma bilobulada con una fuerte escotadura central, con 12 setas ubicadas en la superficie externa y 6 en la cara interna; espínulas de la epifaringe densas y alargadas, concentradas desde su centro hacia la base del labro. Mandíbulas fuertemente quitinizadas con 5 dientes, siendo los 4 primeros de forma aguzada. Espinerete corto de forma subtriangular y levemente curvo. Palpos labiales cilíndricos y alargados, menor a la mitad del largo, con respecto al espinerete. Protórax con placa torácica destacada de textura reticulada, de color verde claro, con surco medio dorsal presente y destacado; espiráculo de forma circular. Patas de color similar al resto del cuerpo y con garra del tarso simple. Abdomen con espiráculos de forma circular, siendo el de A8 de tamaño mayor en diámetro que los precedentes y separado menor a la mitad de su diámetro del pináculo. Espuripedios con crochets dispuestos en bandas biordinales. Placa anal bien diferenciada, textura reticulada, de color similar al resto del cuerpo; peine anal presente, fuertemente quitinizado, compuesto de 6 a 9 dientes. Tegumento cubierto de densos microprocesos de forma circular y pequeña espina distal.

Antena: Primer segmento anular, poco quitinoso y corto. Segundo segmento cilíndrico, alongado, poco quitinoso,

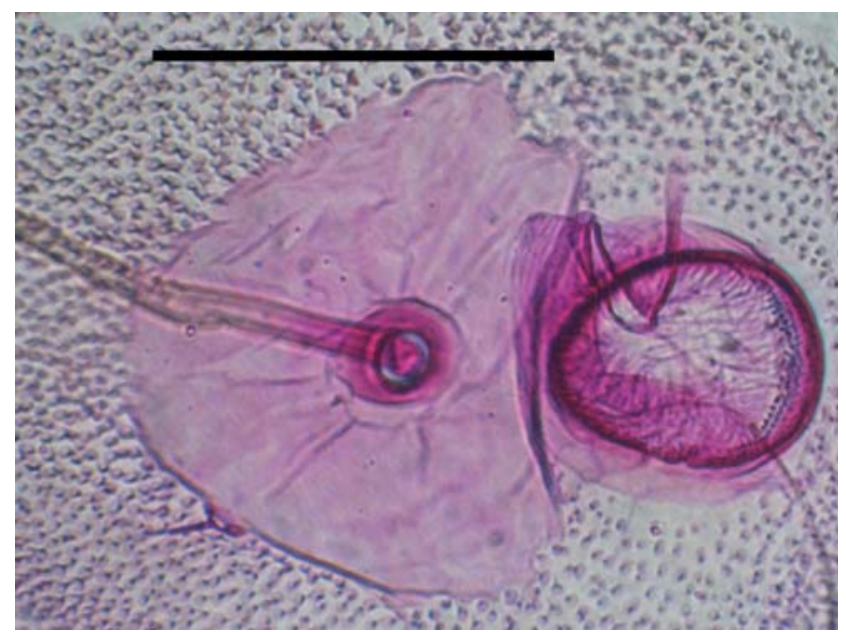

FIgURA 40. Larva de Proeulia auraria. Detalle de pináculo de SD1 y espiráculo en A8. Escala: 0,25 mm.

FIgURE 40. Proeulia auraria larvae. Detail SD1, SD2 and spiracle A8. Scale: $0.25 \mathrm{~mm}$.

con tenue reticulación, presenta un sensilo campaniforme, ubicado cerca de la base. Posee además cinco sensilos: dos tricodeos, siendo el más pequeño menor a la mitad del largo respecto del segmento, ubicado en el tercio superior y tres sensilos basicónicos. Tercer segmento cilíndrico, alongado, menor a la mitad del largo respecto del segundo segmento. Además posee tres sensilos, uno estilocónico y dos basicónicos.

\section{Quetotaxia del último estado:}

Cabeza: 6 estemas de forma semicircular. Estema 5 desplazado hacia la zona anterior de la cabeza; seta S1 posteroventral a estema 3; S2 ubicada posteroventral a estema 1; seta S3 ubicada ligeramente posteroventral a seta S2; seta SS2 ubicada posteroventral a estema 5; SS3 ubicada posteroventral a SS2; SS1 anteroventral a SS2; A1, A2, A3 y L1 en ángulo obtuso muy extendido; AF1, AFa y $\mathrm{AF} 2$ presentes; V1, V2, Va y V3 presentes.

Tórax: Protórax con placa torácica bien destacada, surco medio dorsal presente. Seta SD1 más cerca de XD2 que a SD2. Seta MXD1, por lo general, más cerca de D2. Grupo de setas L, inserto en pináculo de forma elíptica, reticulado, anteroventral al espiráculo, el cual es de forma circular; L2, L1 y L3 alineadas. Grupo de setas SV bisetoso, ubicado sobre pináculo ventral al del grupo L. V1 separado de coxa. Mesotórax y metatórax, con grupo de setas D bisetoso, con ambas setas ubicadas sobre un mismo pináculo; D2 posteroventral a D1. Grupo SD bisetoso, ubicadas en 
un mismo pináculo; SD2 anterodorsal a SD1. L2 y L1 ubicadas sobre un mismo pináculo de forma oblonga; L2 anteroventral a L1; L3 ubicada sobre pináculo de forma circular y posterodorsal a L1. Grupo SV unisetoso, sobre pináculo de forma circular y ubicada de forma ligeramente posteroventral al de L3. V1, por lo general en pináculo de forma circular, separado de coxa.

Abdomen: A1 y A2 con grupo D bisetoso, con ambas setas ubicadas sobre pináculos separados, D1 antero dorsal a D2. Grupo SD bisetoso, dorsal a espiráculo y ventral con D1; en A1, SD2 puede o no estar separado a SD1, en cambio en A2, siempre separado. Setas L1 y L2 sobre pináculo ubicado anterodorsal a L3. Grupo SV trisetoso, ubicado en un mismo pináculo. V1 ubicado sobre un amplio pináculo de forma circular. A3-A6 similar a A2, pero con grupo SV sobre pináculo reniforme, ubicado en la base del espuripedio. A7 similar a A2, pero con SV trisetoso, dispuestas de forma subtriangular. A8 similar a A2, pero con $\mathrm{SD}$ bisetoso y por lo general en un mismo pináculo, siendo el diámetro del espiráculo menor a la mitad del diámetro del pináculo y grupo SV bisetoso. En A9 seta D1 sobre un mismo pináculo que SD1. D2 ubicada sobre un gran pináculo de forma subovoidal. Grupo L trisetoso, dispuesto sobre un mismo pináculo. Grupo SV bisetoso. V1 ubicado sobre pináculo de forma circular. A10 con placa anal bien diferenciada, con 4 pares de setas, con SD1, D1 y SD2 formando un ángulo agudo. Grupo L trisetoso.

Variaciones intraespecíficas: Especie bastante estable en su quetotaxia. En dos ejemplares, en segmento A8, con seta SD2 separada a SD1. En otro ejemplar, grupo L de segmento $\mathrm{T} 1$, tetrasetoso.

Hospederos: Han sido citado los siguientes: Prunus armeniaca, Prunus persicae, Prunus domestica, Actinidia deliciosas, Malus domestica, Pyrus communis, Acer pseudoplatanus, Platanus orientalis, Citrus sinensis (González 1989); Pinus radiata (Parra \& Cerda 1991); Caesalpinia paraguarensis, Diospyrus sp., Pinus sp. (Brown \& Passoa 1998),Eriobotryajaponica, Prunus avium, Juglans regia, Diospyros kaki, Acer buergerianum, Podocarpus nubigera, Ulmus sp., Rosa sp., Fuchsia magellanica, Citronella mucronata, Aristotelia chilensis (mal citada como A. maqui) (González 2003). Nuevos antecedentes: Cryptocarya alba, Euonymus sp., Cotoneaster sp., Luma apiculata, Vaccinium corymbosum, Myoschilos oblonga, Gerista sp., Lonicera japonica, Buddleja globosa, Berberis sp., Prunus cerasifera, Viburnum sp., Salix babylonica, Ligustrum sp. y Corylus avellana.

Material examinado: 18 preparaciones microscópicas, Los Niches, provincia de Curicó, Región del Maule, 6 noviembre, 2002, Coll. D.E. Cepeda, crianza de laboratorio, en Euonymus sp. ( 1 ejemplar de $5^{\circ}$ estado); igual localidad, 13 diciembre, 2002, Coll. D.E. Cepeda, crianza de laboratorio, en Podocarpus nubigera ( 1 ejemplar $5^{\circ}$ estado); igual localidad, 28 noviembre, 2008, Coll. G.E. Cubillos, crianza de laboratorio, en Luma apiculata (4 ejemplares de $5^{\circ}$ estado); Nancagua, provincia de Colchagua, Región del Libertador General Bernardo O'Higgins, 25 octubre, 2010, ( 1 ejemplar de $5^{\circ}$ estado); Los Niches, provincia de Curicó, Región del Maule, 31 octubre, 2010, Coll. G.E. Cubillos, crianza de laboratorio, en Myoschilos oblonga (1 ejemplar de $5^{\circ}$ estado); igual localidad, 31 octubre de 2010, Coll. D.E. Cepeda, crianza de laboratorio, en Gerista sp. (1 ejemplar de $5^{\circ}$ estado); igual localidad, 31 octubre, 2010, Coll. D.E. Cepeda, crianza de laboratorio, en Lonicera japonica (1 ejemplar de $5^{\circ}$ estado); igual localidad, 31 octubre, 2010, Coll. D.E. Cepeda, crianza de laboratorio, en Buddleja globosa (1 ejemplar de $5^{\circ}$ estado); igual localidad, 31 octubre, 2010, Coll. G.E. Cubillos, crianza de laboratorio, en Berberis sp. ( 1 ejemplar de $5^{\circ}$ estado); igual localidad, 31 octubre, 2010, Coll. D.E. Cepeda, crianza de laboratorio, en Prunus cerasifera ( 1 ejemplar de $5^{\circ}$ estado); igual localidad, 31 octubre, 2010, Coll. G.E. Cubillos, crianza de laboratorio, en Viburnum sp. (1 ejemplar de $5^{\circ}$ estado); igual localidad, 31 octubre, 2010, Coll. D.E. Cepeda, crianza de laboratorio, en Salix babylonica ( 1 ejemplar de $5^{\circ}$ estado); igual localidad, 31 octubre, 2010, Coll. G.E. Cubillos, crianza de laboratorio, en Cryptocarya alba (2 ejemplares de $5^{\circ}$ estado); igual localidad, 4 enero, 2011, Coll. C. Saravia, en Corylus avellana ( 1 ejemplar de $5^{\circ}$ estado). Un ejemplar $\widehat{\lambda}$, crianza de laboratorio, Los Niches, provincia de Curicó, Región del Maule, larva de $5^{\circ}$ estado 20 noviembre 2002, pupa 2 enero 2003, adulto 20 enero, en Cryptocarya alba, Coll. D.E. Cepeda; un ejemplar + , crianza de laboratorio, igual localidad, larva de $5^{\circ}$ estado 20 noviembre 2002, pupa 12 enero 2003, adulto 30 enero, en Cryptocarya alba, Coll. D.E. Cepeda; un ejemplar $\hat{\partial}$, crianza de laboratorio, igual localidad, larva $5^{\circ}$ estado 28 noviembre 2008, pupa 14 diciembre, adulto 3 enero de 2009, en Luma apiculata, Coll. G.E. Cubillos; un ejemplar $\widehat{\partial}$, crianza de laboratorio, igual localidad, larva de $5^{\circ}$ estado, 28 noviembre 2008, pupa 12 de diciembre, adulto 3 enero de 2009, en Luma apiculata, Coll. G.E. Cubillos; un ejemplar $q$, crianza de laboratorio, igual localidad, larva de $5^{\circ}$ estado 28 noviembre 2008, pupa 12 diciembre, adulto 3 enero 2009, en Luma apiculata, Coll. G.E. Cubillos; un ejemplar $\widehat{\partial}$, crianza de laboratorio, igual localidad, larva de $5^{\circ}$ estado, 28 noviembre 2008, pupa 18 diciembre, adulto 3 enero de 2009, en Cotoneaster sp., Coll. D.E. Cepeda; un ejemplar $\hat{\partial}$, crianza de laboratorio, Lara Bullileo, provincia de Linares, Región del Maule, larva de $5^{\circ}$ estado, diciembre de 2009, adulto enero 2010, en Vaccinium corymbosum, Coll. K. Buzzetti; un ejemplar $\widehat{\partial}$, crianza de laboratorio, igual localidad, larva de $5^{\circ}$ estado, 31 octubre, pupa 20 noviembre, adulto 18 diciembre de 2010, en Ligustrum sp., Coll. G.E. Cubillos; un ejemplar $\widehat{\partial}$, 
crianza de laboratorio, igual localidad, larva de $5^{\circ}$ estado, 31 octubre, pupa 26 noviembre, adulto 25 diciembre de 2010, en Viburnum sp., Coll. D.E. Cepeda; un ejemplar ${ }^{~}$, crianza de laboratorio, igual localidad, larva de $5^{\circ}$ estado, 31 octubre, pupa 22 noviembre, adulto 15 de diciembre de 2010, en Aristotelia chilensis, Coll. D.E. Cepeda; un ejemplar + , crianza de laboratorio, igual localidad, larva de $5^{\circ}$ estado 31 octubre, pupa 27 noviembre, adulto 13 diciembre de 2010, en Aristotelia chilensis, Coll. D.E. Cepeda; un ejemplar ô, crianza de laboratorio, igual localidad, larva de $5^{\circ}$ estado, 31 octubre, pupa 27 noviembre, adulto 12 diciembre de 2010 , en Myoschilos oblonga, Coll. G.E. Cubillos, un ejemplar + , crianza de laboratorio, igual localidad, larva de $5^{\circ}$ estado, 31 octubre, pupa 3 diciembre, adulto 26 diciembre de 2010, en Myoschilos oblonga, Coll. G.E. Cubillos; un ejemplar ô, crianza de laboratorio, igual localidad, larva de $5^{\circ}$ estado, 31 octubre, pupa 24 noviembre, adulto 16 diciembre de 2010, en Cryptocarya alba, Coll. D.E. Cepeda; un ejemplar , , crianza de laboratorio, igual localidad, larva de $5^{\circ}$ estado 31 octubre, adulto 22 diciembre de 2010, en Aristotelia chilensis, Coll. G.E. Cubillos.

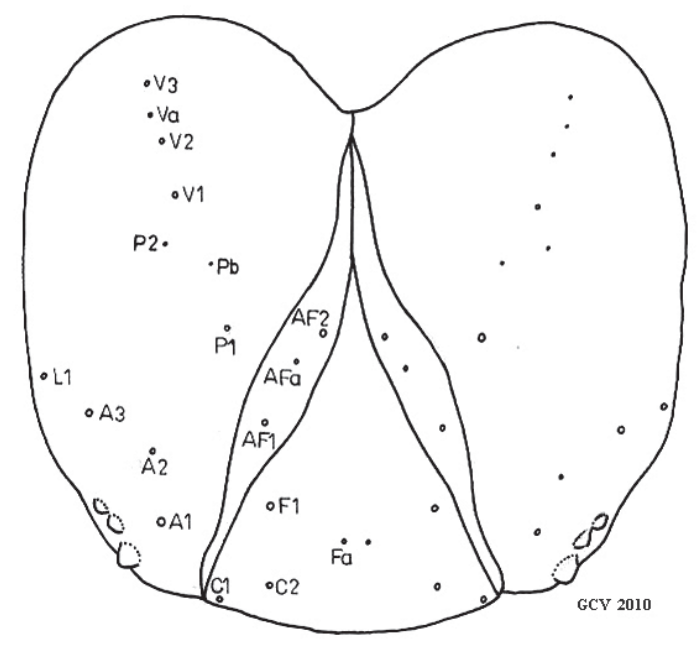

FIgURA 41. Larva de Proeulia chrysopteris. Quetotaxia de cabeza en vista frontal. Escala: 0,5 mm.

FIGURE 41. Proeulia chrysopteris larvae. Chaetotaxy of head in frontal view. Scale: $0.5 \mathrm{~mm}$.

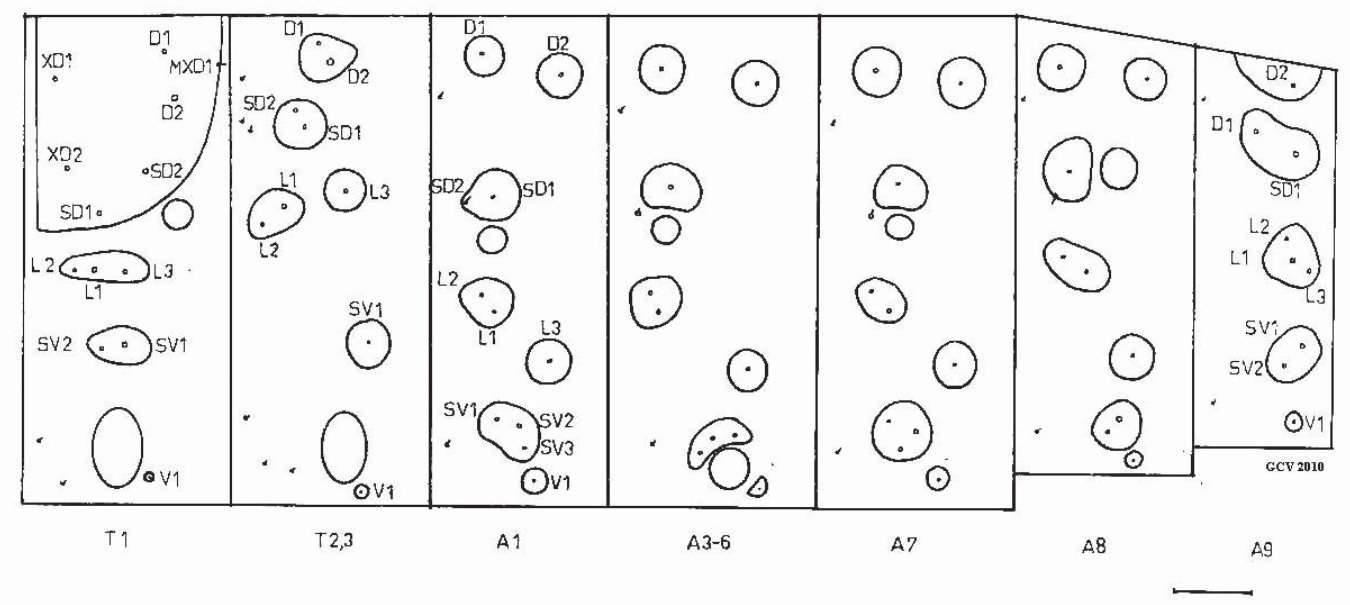

FiguRA 42. Larva de Proeulia chrysopteris. Quetotaxia de tórax y abdomen en vista lateral. Escala: 0,5 mm.

Figure 42. Proeulia chrysopteris larvae. Chaetotaxy of thorax and abdomen in lateral view. Scale: $0.5 \mathrm{~mm}$. 


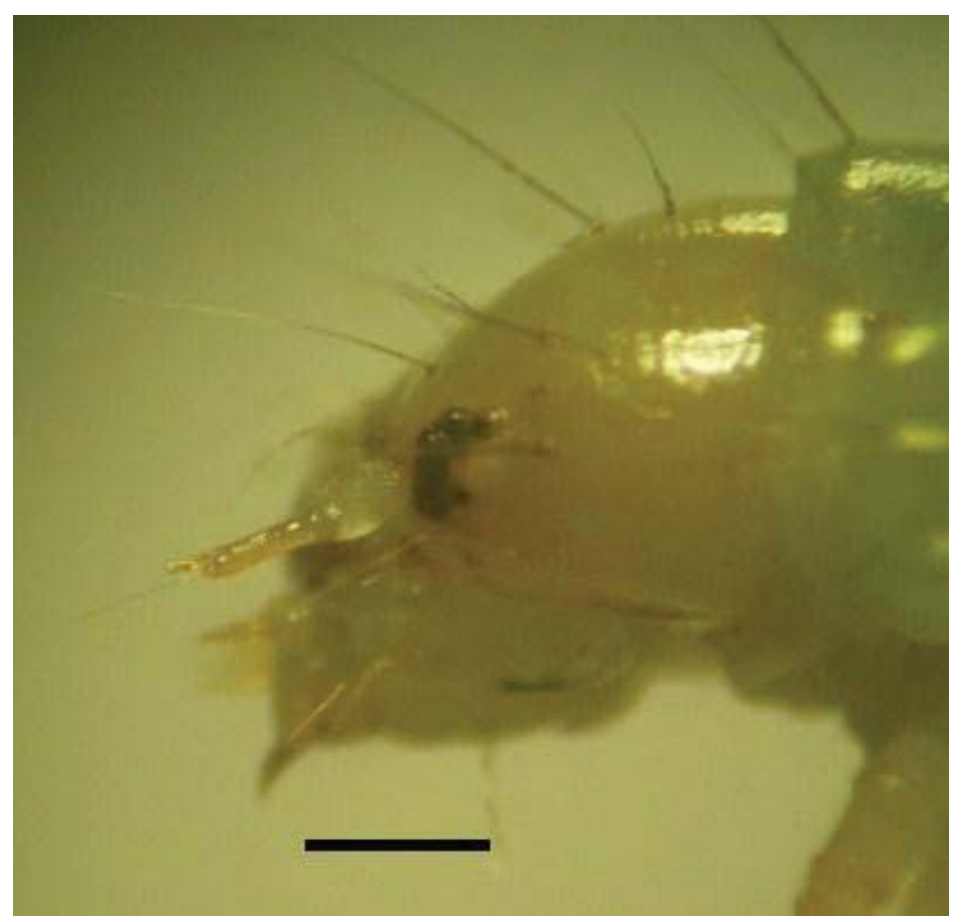

Figura 43. Larva de Proeulia chrysopteris. Detalle de cabeza en vista lateral. Escala: 0,5 mm.

FIgURE 43. Proeulia chrysopteris larvae. Detail of head in lateral view. Scale: $0.5 \mathrm{~mm}$.

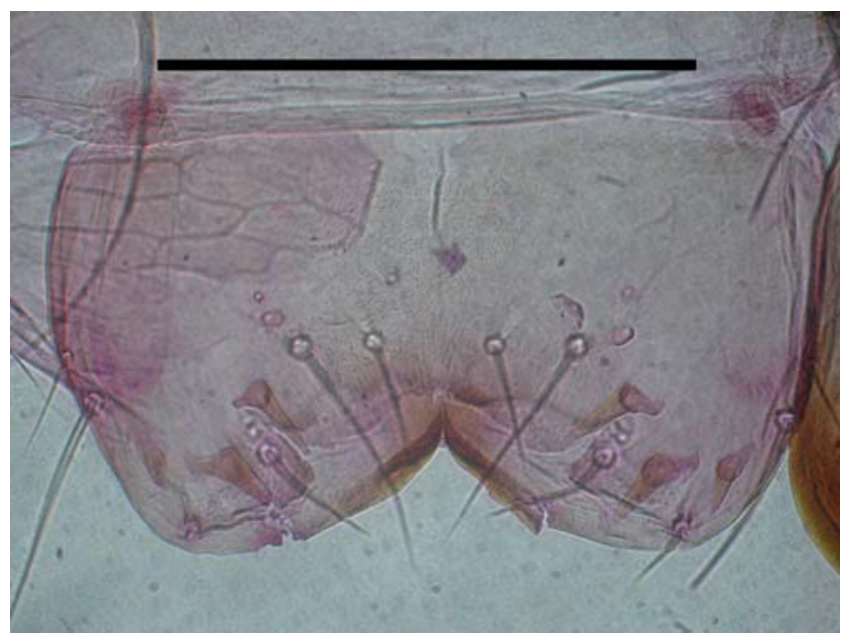

Figura 44. Larva de Proeulia chrysopteris. Labro. Escala: 0,5 mm.

Figure 44. Proeulia chrysopteris larvae. Labrum. Scale: $0.5 \mathrm{~mm}$.

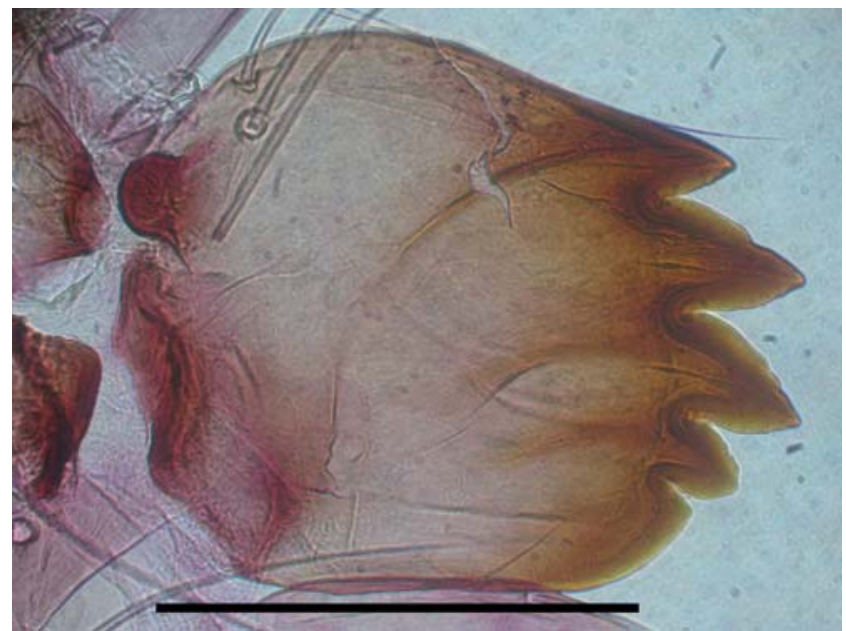

FIgura 45. Larva de Proeulia chrysopteris. Mandíbula. Escala: 0,5 $\mathrm{mm}$.

FIgURE 45. Proeulia chrysopteris larvae. Mandible. Scale: 0.5 $\mathrm{mm}$. 


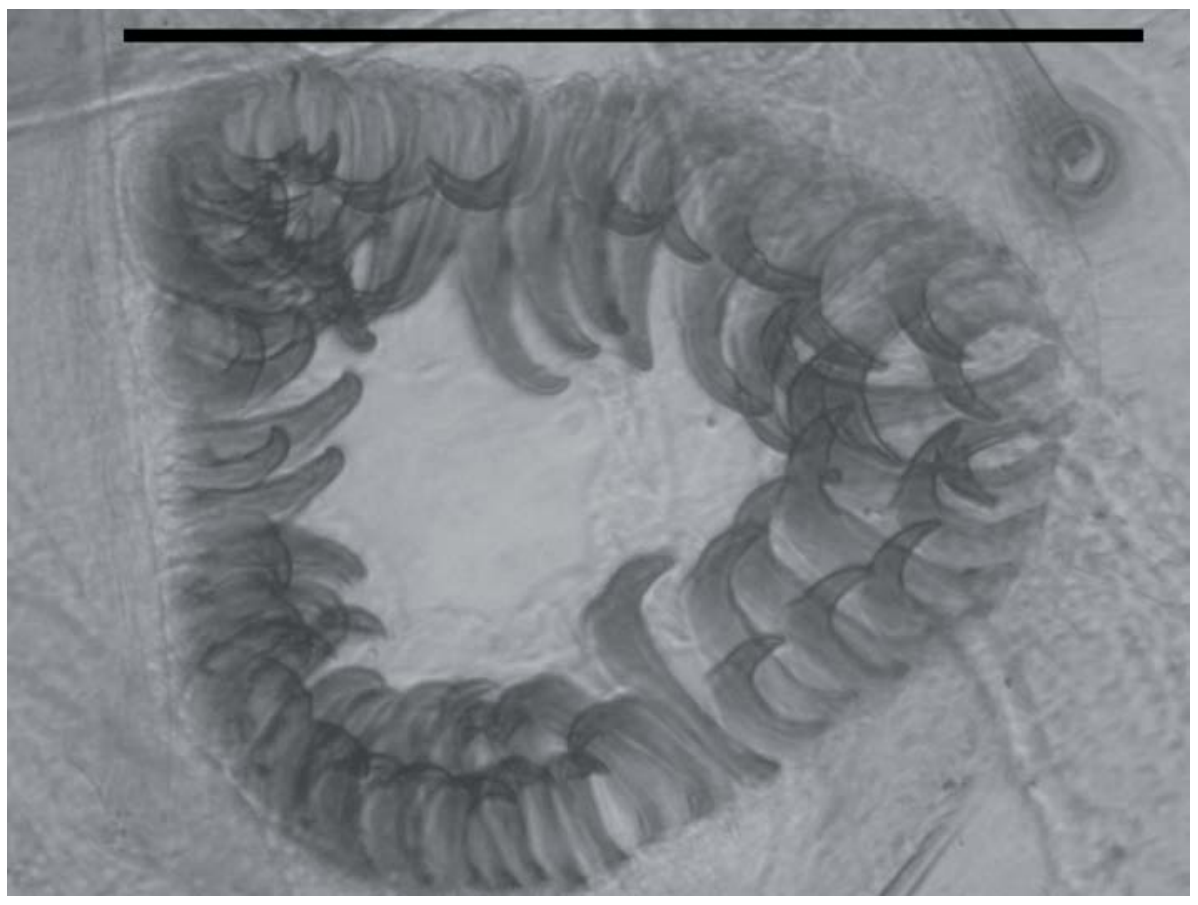

FIgURA 46. Larva de Proeulia chrysopteris. Crochets. Escala: 0,5 mm.

FIgure 46. Proeulia chrysopteris larvae. Crochets. Scale: $0.5 \mathrm{~mm}$.

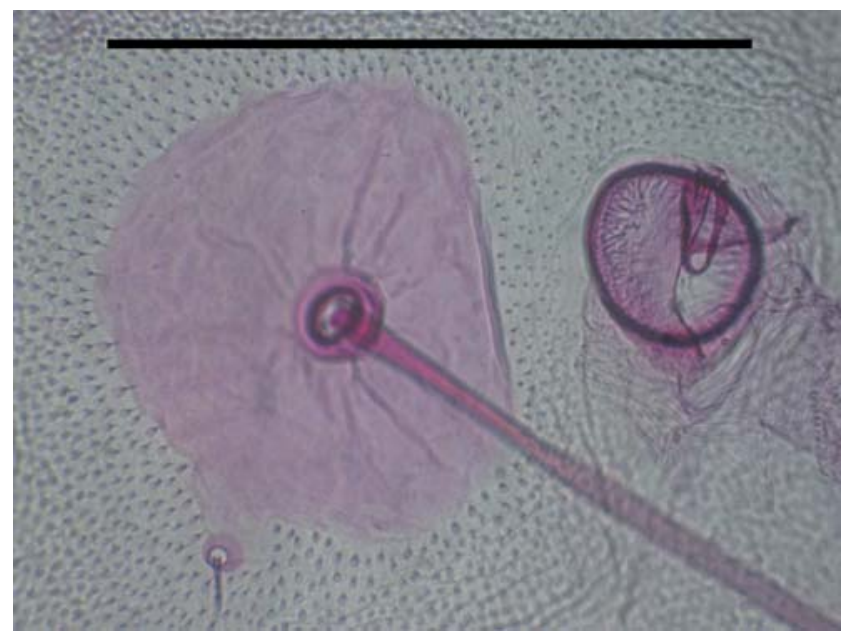

Figura 47. Larva de Proeulia chrysopteris. Detalle de SD1, SD2 y espiráculo en A8. Escala: 0,5 mm.

Figure 47. Proeulia chrysopteris larvae. Detail SD1, SD2 and spiracle on A8. Scale: $0.5 \mathrm{~mm}$.

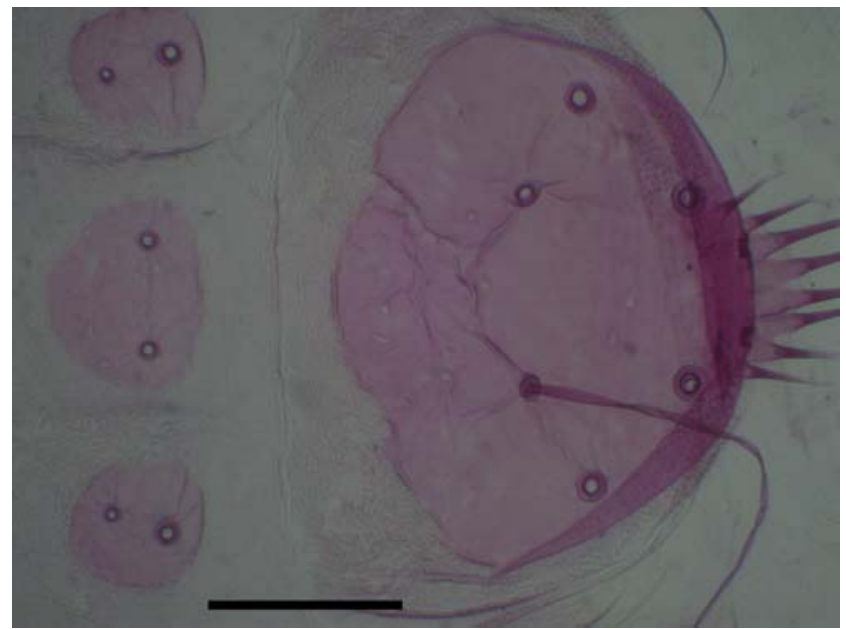

Figura 48. Larva de Proeulia chrysopteris. Detalle de A9 y A10 en vista dorsal. Escala: $0,5 \mathrm{~mm}$.

FIgURE 48. Proeulia chrysopteris larvae. Detail A9 and A10 in dorsal view. Scale: $0.5 \mathrm{~mm}$. 


\section{Proeulia triquetra Obraztsov}

(Figuras 49 - 56)

Diagnosis: Larva de color general del cuerpo verde claro, longitud máxima de $24 \mathrm{~mm}$. Cabeza de color castaño verdoso; antenas con primer segmento con una banda incompleta de tonalidad oscura; segundo y tercer segmentos de color castaño claro. Zona estematal oscura, en especial estemas 3,4 y 5 , rodeado de un área de tonalidad más clara; sin banda en la zona de la gena. Clípeo de tonalidad clara; labro bicolor con una mancha en $\mathrm{V}$ invertida, de forma bilobulada con una gran escotadura en su centro, con 12 setas ubicadas en la superficie externa y 6 en la cara interna; espínulas de la epifaringe densas y alargadas, concentradas desde el centro hacia la base del labro. Mandíbulas fuertemente quitinizadas con 5 dientes, siendo 4 de forma aguda. Espinerete corto de forma subcilíndrica, de ápice redondeado, de color castaño oscuro; palpos labiales cilíndricos y alargados, menor a la mitad del largo con respecto al espinerete. Protórax con placa torácica destacada, de color similar al resto del cuerpo, con surco medio dorsal presente y notorio; espiráculo de forma ovoidal. Patas similares al color del cuerpo y con garra del tarso simple, corta y ancha. Abdomen con espiráculos de forma ovoidal, siendo el de A8 de tamaño mayor en diámetro que los precedentes y separado cerca de la mitad de su diámetro del pináculo. Espuripedios con crochets dispuestos en bandas biordinales. Placa anal bien diferenciada, de forma semicircular, de color similar al cuerpo. Peine anal presente, fuertemente quitinizado, compuesto de 7- 9 dientes. Tegumento del cuerpo cubierto de microprocesos espinosos, cortos y poco densos.

Antena: Primer segmento anular y corto. Segundo segmento cilíndrico, alongado, con tenue reticulación, presenta un destacado sensilo campaniforme y ubicado cerca de la base. Posee además cinco sensilos: dos tricodeos, siendo el más pequeño menor a la mitad del largo respecto del segmento, ubicado en el tercio superior y tres sensilos basicónicos. Tercer segmento cilíndrico, alongado, menor a la mitad del largo respecto del segundo segmento. Además posee de tres a cuatro sensilos, uno estilocónico y dos o tres basicónicos.

\section{Quetotaxia del último estado:}

Cabeza: 6 estemas de forma semicircular. Estema 5 desplazado hacia la zona anterior de la cabeza; seta S1 ubicado ventral a estema 2; S2 ubicada posteroventral a estema 1; seta S3 ubicada levemente posteroventral a seta S2; seta SS2 ubicada posteroventral a estema 5; seta SS3 ubicada posteroventral a SS2; SS1 ubicada anteroventral a SS3; A1, A2, A3 y L1 ubicadas en ángulo obtuso muy extendido; AF1, AFa y AF2 presentes; V1, V2, Va y V3 presentes.

Tórax: Protórax con placa torácica bien destacada con textura reticulada, surco medio dorsal presente. SD1 por lo general cercana a SD2 o equidistante. Seta MXD1 equidistante a D1 y D2. Grupo de setas L, inserto en pináculo de forma elíptica, anteroventral al espiráculo, el cual es de forma ovoidal, setas L2, L1 y L3 alineadas. Grupo de setas SV bisetoso, ubicado sobre pináculo ventral al del grupo L. V1 ubicado en pináculo separado de forma circular. Mesotórax y metatórax, con grupo de setas D bisetoso, con ambas setas ubicadas sobre un mismo pináculo; D2 ventral a D1. Grupo SD, bisetoso, ubicadas en un mismo pináculo, SD2 anterodorsal a SD1. L2 y L1 ubicadas sobre un mismo pináculo, L2 levemente anteroventral a L1, L3 ubicada sobre pináculo de forma subcircular y posterodorsal a L1. Grupo SV unisetoso y ubicada de forma posteroventral al de L3. V1 ubicado sobre la base de la coxa.

Abdomen: A1 y A2 grupo D bisetoso, con ambas setas ubicadas sobre pináculos separados, D1 antero dorsal a D2. Grupo SD bisetoso, ligeramente postero dorsal a espiráculo y ventral con D1; por lo general en A1, SD2 separada a SD1 y en A2, siempre separado. Setas L1 y L2 sobre pináculo ubicado antero dorsal a L3, con L1 postero ventral a L2. Grupo SV trisetoso, ubicado en un mismo pináculo. V1 ubicado sobre un amplio pináculo de forma circular. A3-A6 similar a A2, pero con grupo SV sobre pináculo reniforme, ubicado en la base del espuripedio. A7 similar a A2, pero con grupo SV trisetoso, dispuestas de forma triangular. A8 similar a A1 y A2, pero con grupo SD bisetoso; por lo general, con SD2 separada a SD1, siendo el diámetro del espiráculo mayor a la mitad del diámetro del pináculo y grupo SV bisetoso. En A9 seta D1 en pináculo separado a SD1. Seta D2 ubicada sobre un pináculo de forma subtriangular. Grupo L trisetoso, dispuesto sobre un mismo pináculo. Grupo SV bisetoso. V1 ubicado sobre pináculo de forma circular. A10, con placa anal bien diferenciada y reticulada; con 4 pares de setas, con SD1, D1 y SD2 formando un ángulo agudo. Grupo L trisetoso ubicado en pináculo de forma oblonga.

Variaciones intraespecíficas: En los ejemplares observados se pudo apreciar que en la placa torácica, seta SD1 puede estar equidistante o más cerca de SD2 o cercana a XD2. También se observó que en segmento A1, la seta SD2 estaba junto a SD1, pero a un solo lado. En un ejemplar, en segmento A8, seta SD2 en un mismo pináculo que SD1.

Hospederos: Esencialmente ha sido citada para Vitis vinifera (González 1983; Brown \& Passoa 1998); Malus domestica (González 1989); Hebe sp., Rubus occidentalis (González 2003). Nuevos antecedentes: Citrus reticulata, Myoschilus oblonga, Convolvulus arvensis, Maytenus boaria, Lonicera japónica, Prunus cerasifera, Buddleja davidii y Fuchsia magellanica. 
Material examinado: 11 preparaciones microscópicas, Los Niches, provincia de Curicó, Región del Maule, 6 noviembre, 2002, Coll. D.E. Cepeda, crianza de laboratorio, en Hebe sp. (1 ejemplar de $5^{\circ}$ estado); Panquehue, provincia de San Felipe de Aconcagua, Región de Valparaíso, 28 septiembre, 2010, Coll. D.E. Cepeda, crianza de laboratorio, en Citrus reticulata (2 ejemplares de $5^{\circ}$ estado); igual localidad, 14 octubre, 2010, Coll. D.E. Cepeda, crianza de laboratorio, en Citrus reticulata ( 1 ejemplar de $3^{\text {er }}$ estado); Los Niches, provincia de Curicó, Región del Maule, 31 octubre, 2010, Coll. D.E. Cepeda, crianza de laboratorio, en Myoschilos oblonga ( 1 ejemplar de $5^{\circ}$ estado); igual localidad, 31 octubre, 2010, Coll. D.E. Cepeda, crianza de laboratorio, en Convolvulus arvensis ( 1 ejemplar de $5^{\circ}$ estado); igual localidad, 31 octubre, 2010, Coll. G.E. Cubillos, crianza de laboratorio, en Maytenus boaria (1 ejemplar de $5^{\circ}$ estado); igual localidad, 31 octubre, 2010, Coll. G.E. Cubillos, crianza de laboratorio, en Lonicera japonica (2 ejemplares de $5^{\circ}$ estado); igual localidad, 31 octubre, 2010, Coll. G.E. Cubillos, crianza de laboratorio, en Prunus cerasifera (1 ejemplar de $5^{\circ}$ estado); igual localidad, 31 octubre, 2010, Coll. D.E. Cepeda, crianza de laboratorio, en Buddleja davidii y Fuchsia magellanica (2 cabezas de $5^{\circ}$ estado). Un ejemplar $\hat{\partial}$, crianza de laboratorio, Los Niches, provincia de Curicó, Región del Maule, larva de $5^{\circ}$ estado 6 noviembre 2002, pupa 12-13 noviembre, adulto 24 diciembre, en Hebe sp., Coll. D.E. Cepeda.

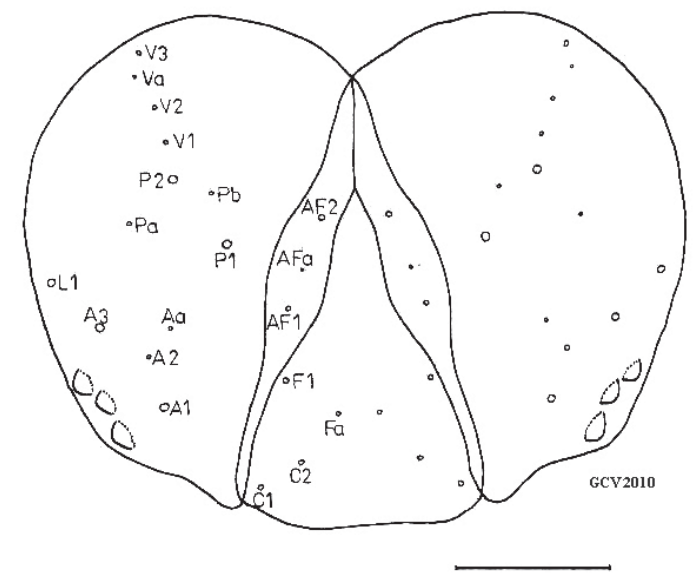

Figura 49. Larva de Proeulia triquetra. Quetotaxia de cabeza en vista frontal. Escala: 0,5 mm.

Figure 49. Proeulia triquetra larvae. Chaetotaxy of head in frontal view. Scale: $0.5 \mathrm{~mm}$.

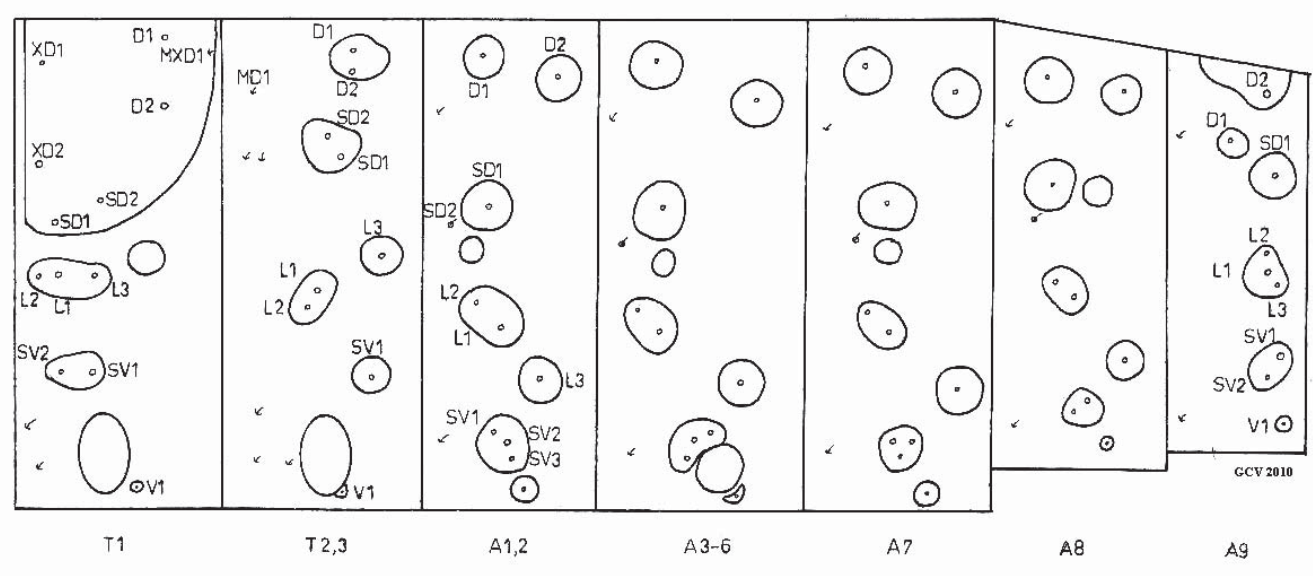

Figura 50. Larva de Proeulia triquetra. Quetotaxia de tórax y abdomen en vista lateral. Escala: 0,5 mm.

Figure 50. Proeulia triquetra larvae. Chaetotaxy of thorax and abdomen in lateral view. Scale: $0.5 \mathrm{~mm}$. 


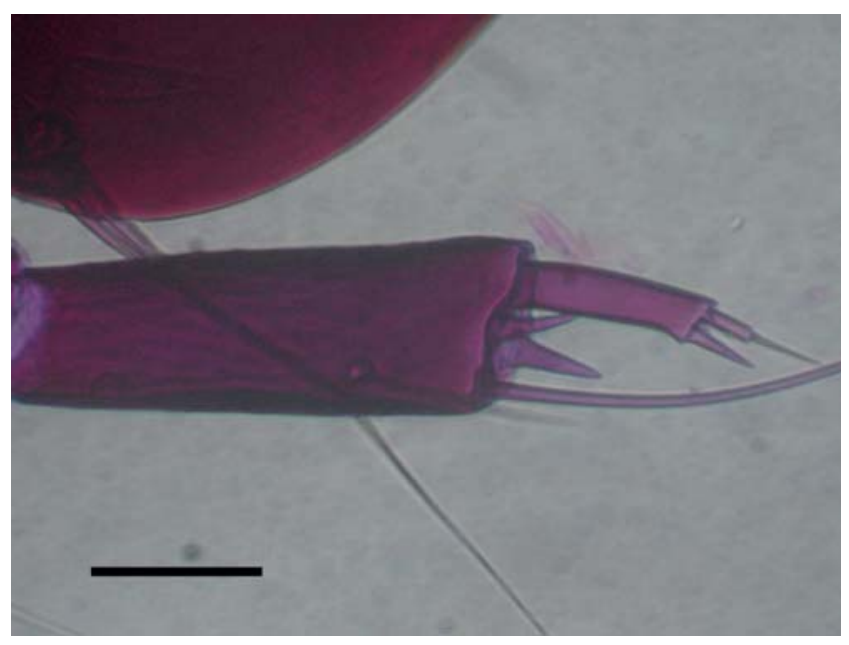

Figura 51. Larva de Proeulia triquetra. Antena. Escala: 0,2 mm.

FIGURE 51. Proeulia triquetra larvae. Antennae. Scale: $0.2 \mathrm{~mm}$.

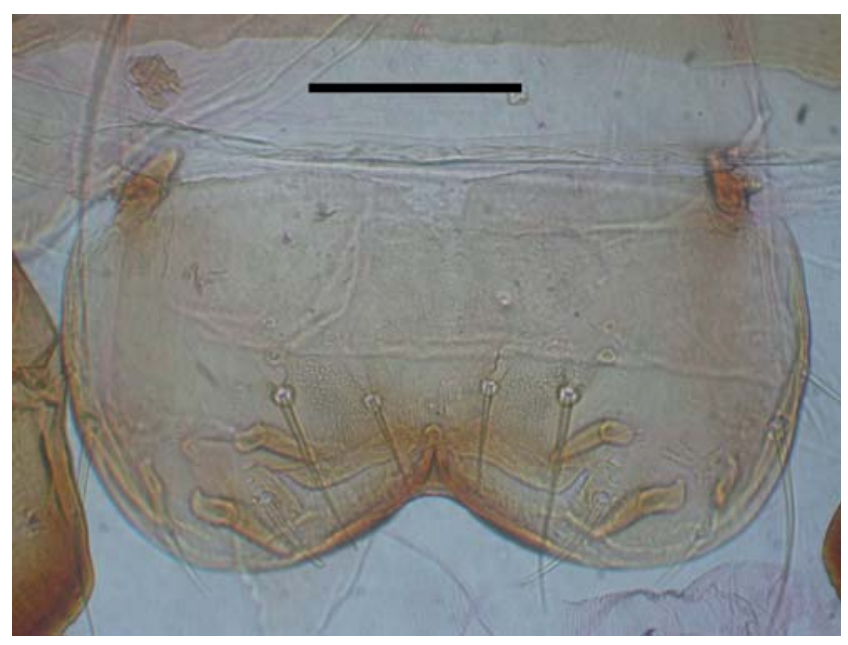

FIgURA 52. Larva de Proeulia triquetra. Labro. Escala: 0,2 mm. Figure 52. Proeulia triquetra larvae. Labrum. Scale: $0.2 \mathrm{~mm}$.

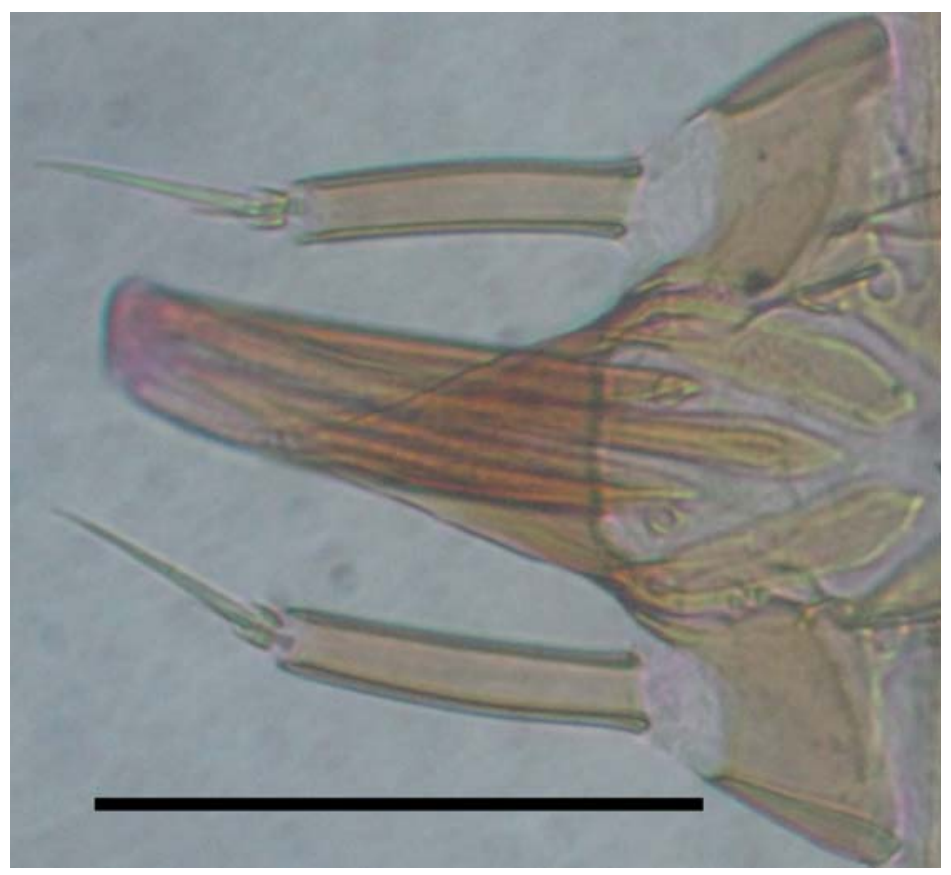

Figura 53. Larva de Proeulia triquetra. Espinerete. Escala: 0,2 mm.

Figure 53. Proeulia triquetra larvae. Spinneret. Scale: $0.2 \mathrm{~mm}$. 


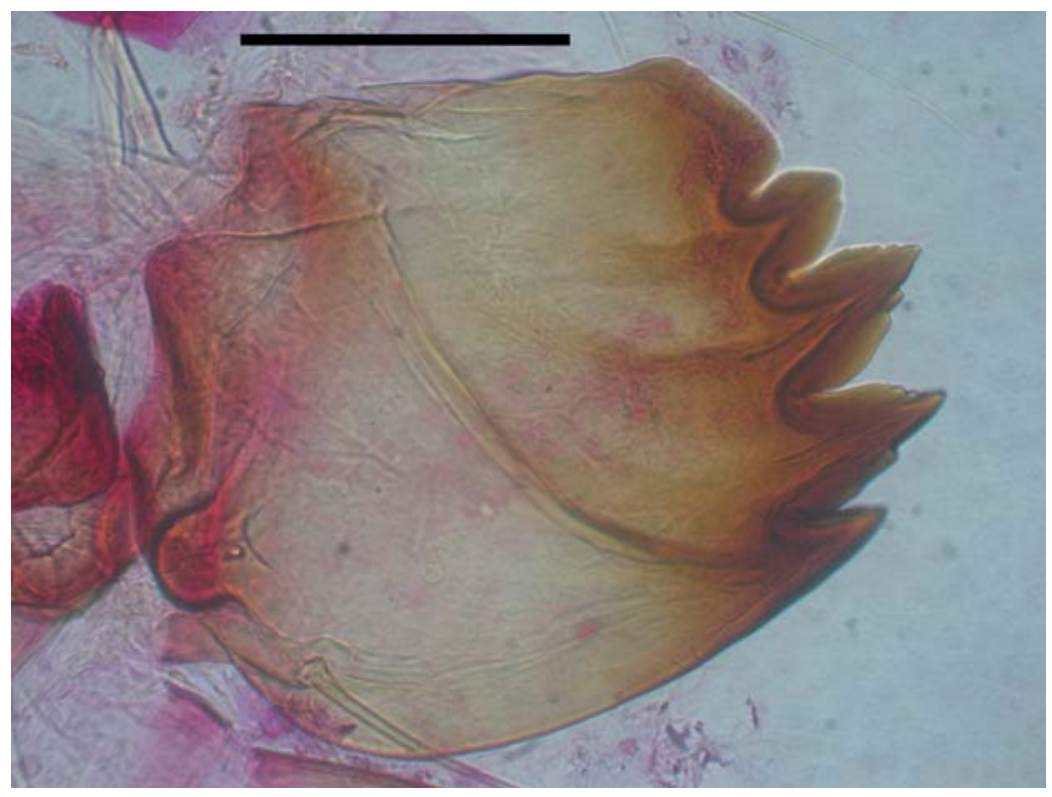

FIgURA 54. Larva de Proeulia triquetra. Mandíbula. Escala: 0,2 mm.

FIGURE 54. Proeulia triquetra larvae. Mandible. Scale: $0.2 \mathrm{~mm}$.

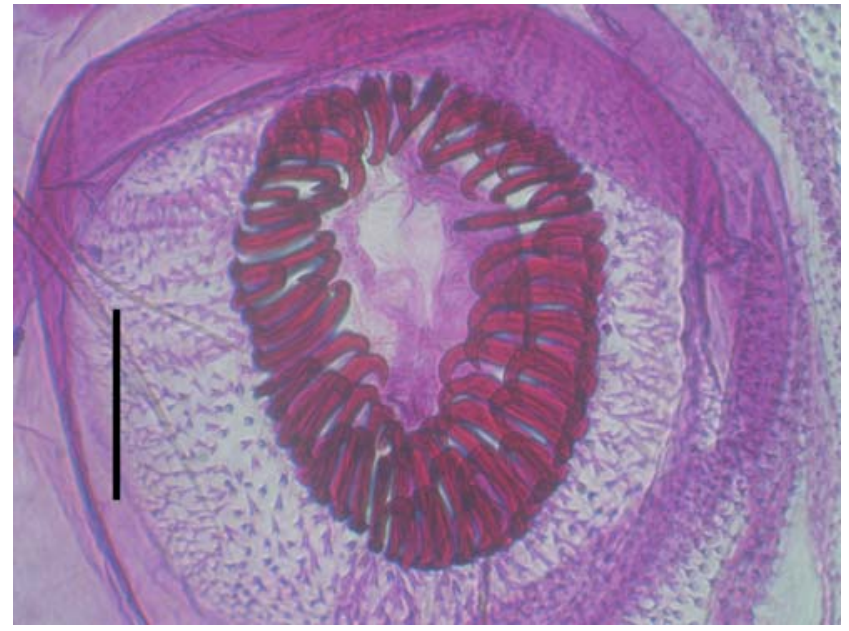

FIgURA 55. Larva de Proeulia triquetra. Crochets. Escala: 0,2 mm.

FIgure 55. Proeulia triquetra larvae. Crochets. Scale: $0.2 \mathrm{~mm}$.

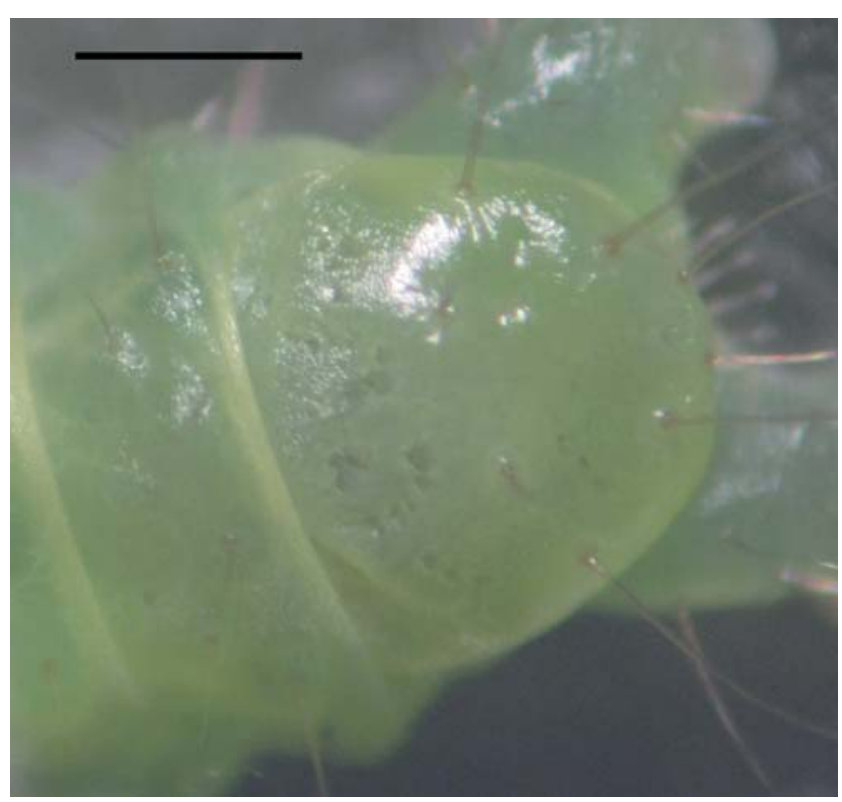

FIgURA 56. Larva de Proeulia triquetra. Placa anal. Escala: 0,5 mm. FIgURE 56. Proeulia triquetra larvae. Anal plate. Scale: $0.5 \mathrm{~mm}$. 


\section{DISCUSIÓN}

En conformidad a los resultados obtenidos, se presenta la primera descripción basada en el estudio de quetotaxia para 5 especies de importancia económica en Chile y se aumenta el registro con nuevos hospederos para 3 especies de Proeulia. En el caso de Lobesia botrana (Denis \& Schiffermüller), resultó ser una especie estable en su quetotaxia y cercana morfológicamente a Paralobesia viteana (Clemens) (polilla de la baya de la uva). Esta importante plaga del cultivo de la vid en EE.UU. (MacKay 1959; Gilligan et. al 2008) no está presente en Chile y representa un significativo riesgo de orden cuarentenario; De la cual es posible diferenciar, por los siguientes caracteres: en segmento A8 la distancia de separación del espiráculo, respecto al pináculo de seta SD1, es mayor al diámetro del espiráculo y en segmento $\mathrm{A} 9$ el pináculo de setas D2 es de forma subtriangular. Respecto de Chileulia stalactitis (Meyrick), taxón nativo de Argentina y Chile, que cuenta con dos especies (Razowski \& Pelz 2010), presenta como carácter morfológico distintivo, el que cada espiráculo del abdomen se encuentra rodeado de un destacado anillo libre de microprocesos del tegumento. Además comparte junto con Proeulia triquetra Obraztsov que en el segmento A9, la seta D1 y SD1 se encuentran en pináculos separados. En cambio, las larvas de Proeulia auraria (Clarke) y Proeulia chrysopteris (Butler), si bien están incluidas bajo la subfamilia Tortricinae, no comparten el carácter morfológico que permite diferenciarlas; ya que ambas setas están ubicadas en un mismo pináculo. Estas observaciones son compartidas y mencionadas para los taxones de Euliini, Anopina (Brown \& Powell 2000) y Seticosta (Brown \& Nishida 2003).

Con las prospecciones de campo realizadas junto a la recopilación de antecedentes previos, se ha logrado actualizar y ampliar los registros de hospederos, lo que se presenta de la siguiente forma: para Proeulia auraria (Clarke), de 19 hospederos citados en la literatura, se citan 9 como primer registro; para Proeulia chrysopteris (Butler), de 24 ya citados, se suman 15 nuevas citas y para Proeulia triquetra Obraztsov, de tan sólo 4 hospederos citados, se reportan 8 nuevos registros. En consecuencia, se puede apreciar un alto grado de polifagia del taxón, característica compartida por varios géneros de la tribu Euliini y reportada por Brown \& Passoa (1998). Según nuestras observaciones, las larvas de Proeulia sp. se comportan de un modo generalista en diversas plantas, con predominio de ornamentales.

\section{AGRADECIMIENTOS}

Trabajo financiado por el Programa de Control Oficial de Lobesia botrana (PCLOB), dependiente del Servicio
Agrícola y Ganadero (SAG). A Paola Favres, por la obtención de bibliografía.

\section{BIBLIOGRAFÍA}

Álvarez, P. \& R.H. GonzÁlez. 1982. Biología de la polilla enrolladora del peral Proeulia auraria (Clarke). Revista Frutícola (3):75-80.

Brown, J.W. \& K. NishidA. 2003. First record of larval endophagy in Euliini (Tortricidae): a new species of Seticosta from Costa Rica. Journal of the Lepidopterits`Society 57(2):113-120.

Brown, J.W. \& S. PassoA. 1998. Larval foodsplants of Euliini (Lepidoptera: Tortricidae): from Abies to Vitis. The PanPacific Entomologist 74(1):1-11.

Brown, J.W. \& J.A. Powell. 2000. Systematic of Anopina Obraztsov (Lepidoptera: Tortricidae: Euliini). University of California Publications in Entomology 120.128 pp +32 pp figs.

Campos, S.L., M.A. Faccin, M.N. Echeverría \& R.L. Sazo. 1981. Distribución y ciclo evolutivo del tortrícido enrollador de la vid Proeulia auraria (Clarke). Agricultura Técnica 41:246-256.

Diario Oficial de la República de Chile. Lunes 28 de abril de 2008, 9 pp.

GonzÁlez, R.H. 1983. Manejo de plagas de la vid. Publicaciones en Ciencias Agrícolas 13:1-115.

GonzÁlez, R.H. 1989. Insectos y Ácaros de importancia Agrícola y Cuarentenaria en Chile. Editorial Ograma, Santiago, Chile. 310 pp.

GonzÁlez, R.H. 1990. Las Eulias de los frutales en Chile. Revista Aconex 27:3-8.

GonZÁLEZ, R.H. 2003. Las Polillas de la fruta en Chile (Lepidoptera Tortricidae; Pyralidae). Serie Ciencias Agronómicas. 9:188.

Hetz, M. \& F. Werner. 1980. Description of the larvae of two Olethreutine moths reared from roots of woody Compositae. Annals of the Entomological Society of America 73(5): 536-540.

Hinton, H.E. 1946. On the homology and nomenclature of setae of lepidopterus larvae, with some notes on the phylogeny of Lepidoptera. Transactions of the Royal Entomological Society of London 97:1-37.

MACKAY M.R.1959. Larvae of the North American Olethreutidae (Lepidoptera). Canadian Entomologist Supplement. 10:1338 pp.

MacKaY M.R.1962. Larvae of the North American Tortricinae (Lepidoptera: Tortricidae). Canadian Entomologist Supplement 28:1-182.

Obraztsov, N.S. 1964. Neotropical microlepidoptera, V. Sinopsis of the species of the genus Proeulia from central Chile (Lepidoptera: Tortricidae). Proceedings of the United States National Museum 116:183-196.

Parra, L.E. \& L.A. Cerda. 1991. Presencia de Proeulia chrysopteris (Butler) (Lepidoptera: Tortricidae) sobre Pinus radiata D. Don. Bosque. 12(2):61-63.

PassoA, S. 2008. Part III: Immature stages. En: Oletrheutine Moths of the Midwestern United States. An Identification Guide. (Eds. Gilligan, T.M., D.J. Wright, and L.D. Gibson). pp: 
301-309. Ohio Biological Survey Bulletin New Series. Volumen XVI, Number 2:334 pp.

Powell, J. 1986. Sinopsis of Classification of Neotropical Tortricinae, with Descriptions of the New Genera and Species (Lepidoptera: Tortricidae). The Pan-Pacific Entomologist 62(4):372-398.

Prado, E. 1988. Notas sobre insectos de importancia agrícola en Chile. Agricultura Técnica. Chile 48(1):51-54.

Razowski, J. 1995. Proeulia Clarke, 1962 the Western neotropical Tortricidae genus (Lepidoptera), with descriptions of five new species and two allied genera. Acta Zoologica Cracoviense 38(2):271-283.

Razowski, J. 1999. Euliini (Lepidoptera: Tortricidae) of Chile. Polskie Pismo Entomologiczne 68:69-90.

Razowski, J. \& V. Pelz. 2010. Tortricidae from Chile (Lepidoptera: Tortricidae). SHILAP Revista de Lepidopterología Sociedad Hispano-Luso-Americana de Lepidopterología 38(149): 5-55.
Stehr, F.W. 1987. Order Lepidoptera. En: Immature Insects. (Eds. F.W.Stehr). p 288-340. Vol.I. Kendall/Hunt publishing company. Dubuqueque, Iowa. 754 pp.

VARgas, H. A. 2006. Descripción de la Larva de Último Instar y de la Pupa de Cryptophlebia cortesi Clarke (Lepidoptera: Tortricidae). Neotropical Entomology 35(3):338-343.

VARgas, H. A. 2007A. Descripción de la larva de último instar y de la pupa de Cydia largo Heppner (Lepidoptera: Tortricidae). Revista Brasileira de Entomología 51(3):263-266.

VARGAS, H. A. 2007B. Larva de último instar, pupa y nuevo registro de distribución de Periploca otrebla Vargas (Lepidoptera: Cosmopterigidae). Neotropical Entomology 36(6):894-901.

Venette, R.C., E. E. Davis, M. Dacosta, H. Heisler \& M. LARSON. 2003. Mini Risk Assessment grape berry moth, Lobesia botrana (Denis \& Schiffermüller) (Lepidoptera: Tortricidae). URL: http://www.aphis.usda.gov/plant health/plant_pest_info/pest_detection/downloads/pra/ lbotranapra.pdf Accesado: 21 junio del 2010.

Recibido: 13.12 .10

Aceptado: 23.03.11 